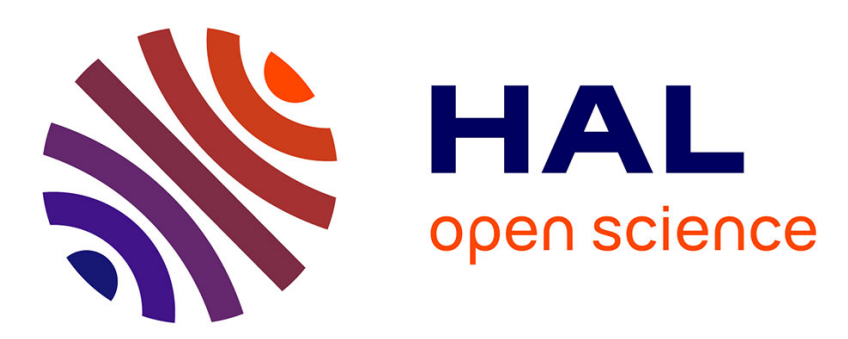

\title{
A holistic approach of numerical analysis of the geology effects on ground motion prediction: Argostoli site test
}

Sara Touhami, Fernando Lopez-Caballero, Didier Clouteau

\section{To cite this version:}

Sara Touhami, Fernando Lopez-Caballero, Didier Clouteau. A holistic approach of numerical analysis of the geology effects on ground motion prediction: Argostoli site test. Journal of Seismology, 2021, 25 (1), pp.115-140. 10.1007/s10950-020-09961-0 . hal-03427394

\section{HAL Id: hal-03427394 \\ https://hal.science/hal-03427394}

Submitted on 13 Nov 2021

HAL is a multi-disciplinary open access archive for the deposit and dissemination of scientific research documents, whether they are published or not. The documents may come from teaching and research institutions in France or abroad, or from public or private research centers.
L'archive ouverte pluridisciplinaire HAL, est destinée au dépôt et à la diffusion de documents scientifiques de niveau recherche, publiés ou non, émanant des établissements d'enseignement et de recherche français ou étrangers, des laboratoires publics ou privés. 


\title{
A holistic approach of numerical analysis of the geology effects on ground motion prediction : Argostoli site test
}

\author{
Sara TOUHAMI - Fernando \\ LOPEZ-CABALLERO · Didier \\ CLOUTEAU
}

Received: date / Accepted: date

\begin{abstract}
When assessing seismic risk at a city scale, local site conditions can significantly modify the destructive potential of an earthquake. This was the case in Mexico City in 1985 and 2017, which is located on a sedimentary valley. For that reason, characterization and consideration of these site effects, in addition to assessing the probability of occurrence of a destructive earthquake in a given region, are crucial. For this purpose, a tri-dimensional model was developed using a numerical code that permit to carry out such kind of studies. The code is based on the spectral element method allowing solving the waves propagation problem in tri-dimensional solid media. The seismic phenomenon is simulated in its entirety: from the seismic source to the site using a representative model of the complexity of the wave path. However, this introduces uncertainties that must be quantified, controlled and reduced by validating the results of the numerical tool with measurements on a real study site. This work aims to study numerically the effect of the geometric structure of soil and subsoil on the prediction of ground motion at the regional scale. The first obtained results show the importance of the in-situ measures on the regional scale simulations.
\end{abstract}

Keywords 3D numerical modelling - Ground motion prediction · Regional model $\cdot$ Spectral Element Method

\section{Introduction}

An accurate prediction of the seismic response of civil engineering structures, especially those of the utmost importance in terms of civil safety, such as hospitals, dams, bridges or nuclear power plants, faces several major difficulties.

Sara TOUHAMI

Laboratoire MSS-Mat CNRS UMR 8579, CentraleSupelec Paris-Saclay University, France

Tel.: + 33-175316 454

E-mail: sara.touhami@centralesupelec.fr 
It is well known that to better characterize the seismic phenomenon several parameters such as site effects (basins, topographie, etc) have to be considered. Indeed, during the wave propagation process, the soil near the surface can have an effect of amplification or de-amplification on the ground motion. This may be related to soil type (soft), geology or soil heterogeneity among others.

Traditional methods for soil motion evaluation use prediction equations developed empirically by regression of seismic recording data. However, in areas of low seismicity like France, there is not enough data to create this type of equation and thus predict the local seismic hazard. These equations are therefore specific to each region of the world. It is then possible to use numerical simulation tools to complete the lack of measured data.

As far as prediction of the seismic motion is concerned, source propagation and site effects have been extensively studied these last two decades (ChávezGarcia et al., 2000; Faccioli et al., 2002; Gatti et al., 2018; Paolucci et al., 2015). Moreover, recent numerical methods such as the Spectral Element Method or the Discontinuous Galerkin Method combined with massively parallel computers have proved to be very effective to modelling the propagation of seismic waves from the source to the site even in complex tri-dimensional geological environments (Liu, 2006; Göddeke et al., 2014). However, the accuracy of such predictions remains limited due to large uncertainties on the data to be introduced in the model, ranging from the geometric and kinematic or dynamic characterization of the seismic source, to the detailed numerical model of the source-to-site propagation path, including possible non-linear response. Even very extensive geophysical surveys fail at reducing the resulting uncertainties on the predicted ground motion. As well, such large-scale surveys cannot be conducted for all practical cases. For this reason, the construction of a regional model that simulates the seismic phenomenon from the source to the structure would make it possible to better analyse the simulated signals.

The seismic hazard is influenced by different effects, from the emission of waves during an earthquake to the studied site. This hazard depends on the heterogeneities of the fracture process at different scales, the wave propagation path and the site effects. On the one hand, at the regional level, the mechanisms of radiation during the rupture and its propagation in the earth's crust characterizing the hazard involve the determination of attenuation laws. On the other hand, at local scale, the geomorphological conditions of a site can considerably intensify the strength of an earthquake by the amplification of the movement of the ground (Cruz-Atienza et al., 2016). The characterization and the consideration of these site effects, related to the soil conditions, are essential for the evaluation of the seismic risk. Site effects are related to the geometric structure of the soil and subsoil. Two types of structures are responsible for the main observed effects: the topography and the sedimentary fillings (e.g. during the 1985 Mexico City and 1995 Kobe earthquake (Pitarka et al., 1996)).

In this paper, the effect of local and global geology on the predicted ground motion is studied numerically via the simulation of a seismic event at the site 
test installed at Kefalonia Island (Greece). One of the goals of this site is to allow the validation of $3 \mathrm{D}$ computational codes by comparing their prediction to real data through the installation of a permanent accelerometric vertical network. For the construction of this numerical model, in addition to a mesh, it is necessary to have two types of data: the characteristics of the seismic source and the geology of the site.

On the one hand, this work aims to present a methodology for building a large-scale 3D numerical model. On the other hand, it aims to study numerically two aspects: the effect of global geology (topography and bathymetry) and local geology (sedimentary basin) on ground motion compared to a traditional manner. In order to highlight the effect of topography and bathymetry on ground motion, a first part of this work focusing on a comparison of three numerical models that have the same stratigraphy : a flatted model, a model including both topography and a model including topography and bathymetry. In addition, to emphasize the influence of the sedimentary fill, a second part of the work concerns a realistic modelling of the Argostoli basin without considering the topographic configuration of the site.

The present work is placed within the framework of the French research project SINAPS (Séismes et Installations Nucléaires, Améliorer et Préserver la Sûreté). This project has been initiated by the members of the institute SEISM after the nuclear disaster of Fukushima (Japan, 2011). It aims to enhance the scientific background in the area of the nuclear safety and radiation protection. The project contains different work packages. The present work is part of the work package "Non-Linear Sites Effects and Soil-Structure Interaction" (Berge-Thierry et al., 2017).

\section{Studied site}

The Argostoli test site located at Kefalonia Island was selected for this study. It is a site of high seismicity which is due to the proximity of the Kefalonia Transform Fault (Sokos et al., 2016). In fact, this fault is a connection boundary close to the island of two subduction troughs: Hellenic Arc in the south and the Adriatic Fault Zone (Louvari et al., 1999) (Figure 1). This site was chosen to carry out geological reconnaissance and geophysical acquisition missions in the framework of SINAPS@ project and the NERA European research program among others (Cultrera et al., 2014). Different site characteristics have motivated this choice, i) the significant seismicity which allows to collect strong movements in a reduced time and ii) the geological configuration of this area, namely the presence of sedimentary basin which is favourable to the occurrence of site's effects. The sedimentary basin (Koutavos) is located south of the capital of the island (Argostoli). It is located at the bottom of a lagoon and filled with quaternary and Pliocene detritic deposits (Cushing et al., 2016). In addition, according to the works of Svay et al. (2017) and Imtiaz et al. (2017), a spatial variability was obtained when the records of installed dense network were analysed. 


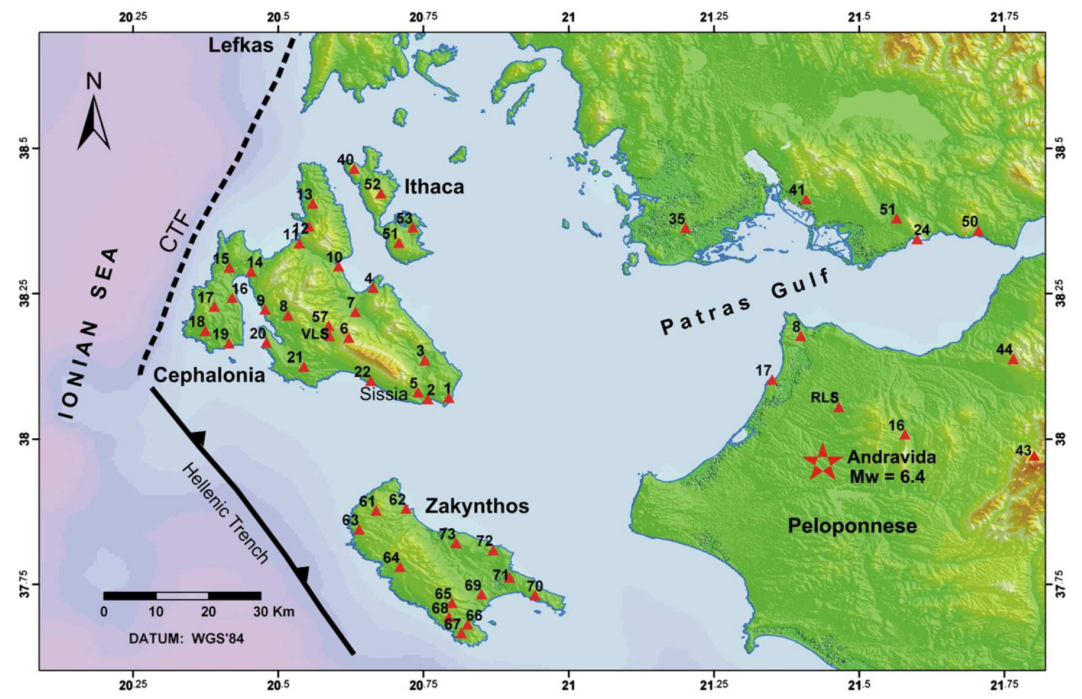

Fig. 1: Principal systems of faults of the Cephalonia island stemming from the seismotectonic map of Greece (IGME). CTF: Cephalonia Transform Fault (Lagios et al., 2012).

\subsection{Geological characteristics}

So as to propagate the waves from the source to the site using a regional scale, it is necessary to define both the crustal and the superficial velocity models (Figure 2). In this work, the model adopted for the study of this region is the 1D profile proposed by Haslinger et al. (1999) (Tab. 1). This profile was obtained by wave-form inversion procedures, centered on the main phase of $\mathrm{P}$-wave. Indeed, local events observed at several stations have been used to calculate a minimum $1 \mathrm{D}$ velocity profile which was verified by several tests (for $\mathrm{P}$ and $\mathrm{S}$ velocity model). Concerning the local scale, a more refined geological model has been obtained by using in situ measurements (Hollender et al., 2015) (Tab. 2). This profile modifies the model proposed by Haslinger et al. (1999) near the ground surface (i.e. from the ground surface to a $5 \mathrm{~km}$ depth). In addition, the velocity profile proposed by Hollender et al. (2015) will be used for the area of the sedimentary basin (Figure 3 ) in order to evaluate the effect of local geology on ground motion prediction. 


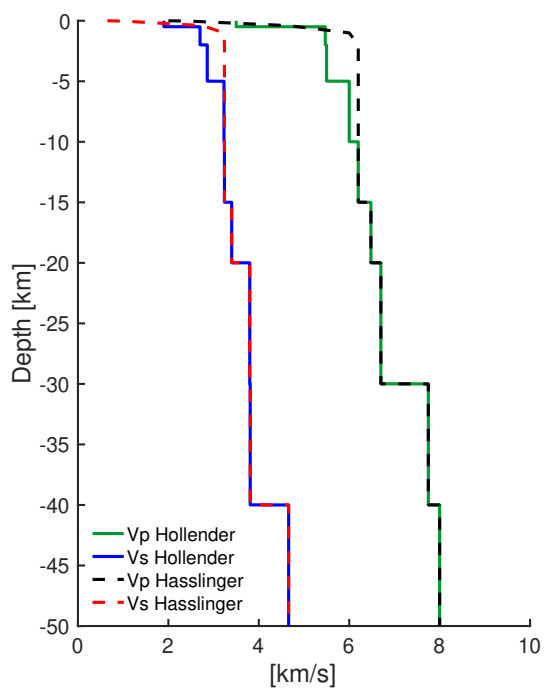

Fig. 2: Crustal model proposed by Haslinger et al. (1999) for Ionian area and velocity profile proposed by Hollender et al. (2015) for Argostoli Area.

Table 1: Values for 1D Crustal model proposed by Haslinger et al. (1999) for Ionian region.

\begin{tabular}{lllll}
\hline Depth $(\mathrm{km})$ & $\mathrm{V}_{p}(\mathrm{~km} / \mathrm{s})$ & $\mathrm{V}_{s}(\mathrm{~km} / \mathrm{s})$ & $\mathrm{Q}_{p}$ & $\mathrm{Q}_{s}$ \\
\hline 0.0 & 3.5 & 1.9 & 300 & 150 \\
0.5 & 5.5 & 2.7 & 300 & 150 \\
2.0 & 5.5 & 2.9 & 300 & 150 \\
5.0 & 6.0 & 3.2 & 300 & 150 \\
10.0 & 6.2 & 3.2 & 300 & 150 \\
15.0 & 6.5 & 3.4 & 300 & 150 \\
20.0 & 6.7 & 3.8 & 300 & 150 \\
30.0 & 6.8 & 3.8 & 300 & 150 \\
40.0 & 8.0 & 4.7 & 1000 & 500 \\
\hline
\end{tabular}

Table 2: Values for velocity model proposed by Hollender et al. (2015) for Argostoli Area.

\begin{tabular}{lllll}
\hline Depth $(\mathrm{km})$ & $\mathrm{V}_{p}(\mathrm{~km} / \mathrm{s})$ & $\mathrm{V}_{s}(\mathrm{~km} / \mathrm{s})$ & $\mathrm{Q}_{p}$ & $\mathrm{Q}_{s}$ \\
\hline 0.0 & 2.0 & 0.6 & 300 & 150 \\
0.03 & 2.4 & 1.0 & 300 & 150 \\
0.4 & 4.6 & 2.7 & 300 & 150 \\
1.0 & 6.0 & 3.2 & 300 & 150 \\
2.0 & 6.2 & 3.2 & 300 & 150 \\
\hline
\end{tabular}


(a)

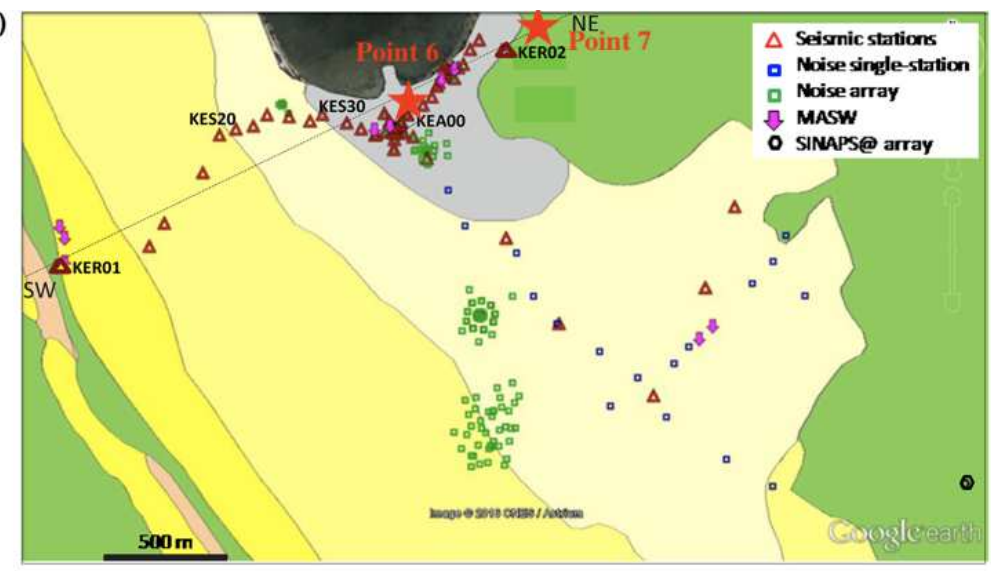

(b)

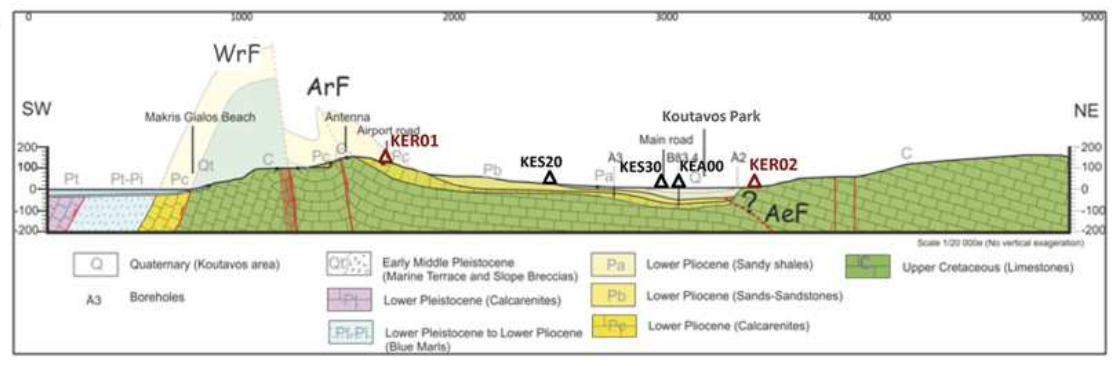

Fig. 3: (a) Plan view of the Argostoli basin together with the seismic array configuration. Contour lines of the geological map correspond to Quaternary (grey), Calcarenites (yellow), Sands-Sandstones (light yellow), Limestones (green), Miocene formation (pink) and they have been constrained using field data (NERA Deliverable D11.3). (b) geological cross-section across the basin (Hollender et al., 2015). 


\section{Database description}

It is well known that the sedimentary fill can drastically change the site response in case of strong ground motions. For this reason, it is necessary to validate the evaluation practices by comparing simulation results to real data. In this sense, a series of accelerometers was installed along a vertical array (and in a rock reference site) within the small sedimentary basin of Koutavos. This array is fully operational and has recorded hundreds of high-quality accelerograms (Figure 4), with PGA sometimes up to $0.15 \mathrm{~g}$ (local $M_{w} 3$-4 events, and a distant $M_{w} 6.5$ event) (Perron et al., 2018a; Cushing et al., 2016; Sbaa et al., 2017).

This vertical array is a long-term investment toward the constitution of a new database for a possible non-linear practice validation in a $3 \mathrm{D}$ case. This site was chosen thanks the feedback of previous works, especially the NERA European research program. It has been installed in July 2015, and consists of 4 downhole, 3-component sensors, complemented by two surface sensors, one at the mouth of the borehole, and the other a few hundred meters away on a rock outcrop. More details concerning both technical characteristics of equipments and the recorded data from this database are available in Perron et al. (2018a); Cushing et al. (2016); Sbaa et al. (2017); Berge-Thierry et al. (2019)
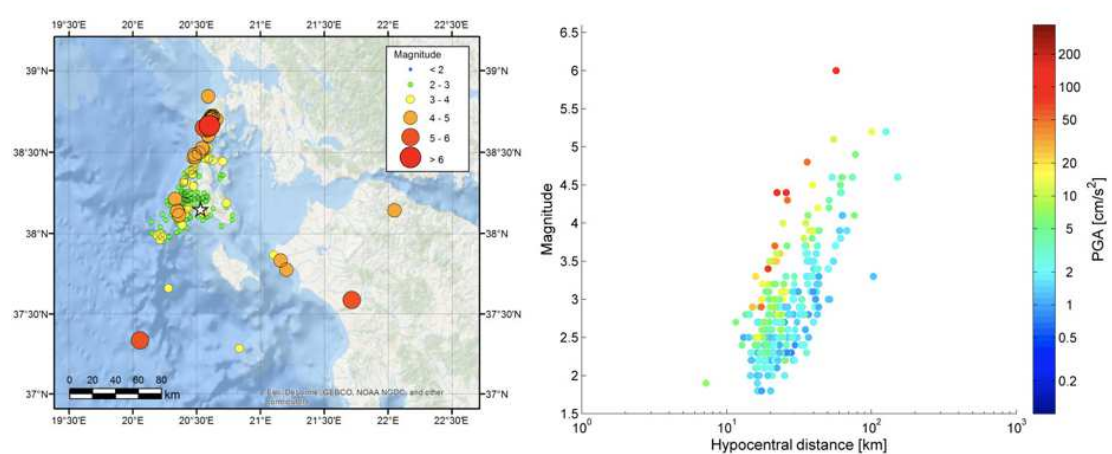

Fig. 4: Epicenters of aftershocks recorded by the Argostoli rock-site dense array and used in the present study. Colors indicate magnitude values. The white star represents the location of the array.

\section{Numerical tools}

The physics-based simulation of realistic earthquake scenarios requires a reliable estimation of several different parameters to reduce uncertainties, related 
to the source mechanism, geological configuration and mechanical properties of soil. Due to the scale of the considered problem, the degree of uncertainty associated with the whole earthquake process (from fault to site) is extremely high. On that account, it appears necessary to build up a multi-tool virtual laboratory to construct and calibrate the seismological model (Figure 5). In this work, the 3D Spectral Elements Method code SEM3D was used to compute numerically the propagation of elastic waves in the medium (solid or fluid). The spectral element method (SEM), initially introduced in the field of fluid mechanics (Patera, 1984; Mayday et al., 1989), was applied to elastodynamics later. This variational method based on a Galerkin approximation is an elegant formulation of the finite element method using a high-order polynomials degree. Similar to the FEM method, the SEM method has a flexibility that allows it to deal with problems with complex geometries. This numerical method has already been applied to the 2D and 3D cases of elastodynamics (Komatitsch, 1997; Faccioli et al., 1997; Komatitsch and Vilotte, 1998; Chaljub et al., 2003). These applications have shown that high precision and low numerical dispersion can be obtained. The SEM method has also proven its efficiency in global seismology for 3D models (Komatitsch et al., 2005; Chaljub et al., 2007).

Among the advantages of SEM3D, its efficient and cost-effective massively parallel implementation (by Message Passing Interface, MPI) on large supercomputers and its ability to accurately take into account 3D discontinuities such as the sediment-rock interface. The original core of the SEM3D software allowed to solve the wave propagation problem in any velocity model, including anisotropy and intrinsic attenuation. To carry out these types of simulations, several issues must be tackled:

- Meshing the domain of interest, its geological conformation (bedrock to sediment geological surfaces), the topographical surface and the bathymetry (if present).

- Representation of the material rheology and heterogeneity of the soil properties.

- Description of the triggering of the seismic source.

To deal with the problem of simulations of seismic scenarios at large scale ( 10-100 km), an efficient meshing tool must tackle the following difficulties:

- Meshing the topographical surface and eventually the coastline and the sea bottom.

- Consider geological discontinuities (typically sedimentary basins, folded geological strata, fault segments).

- Reach a sufficient refinement close the topographical surface, where slower soil strata are naturally found, so to preserve the maximum frequency propagated by the numerical model.

In this part, will be presented the numerical tools as well as the methodology set up to build the numerical model. 


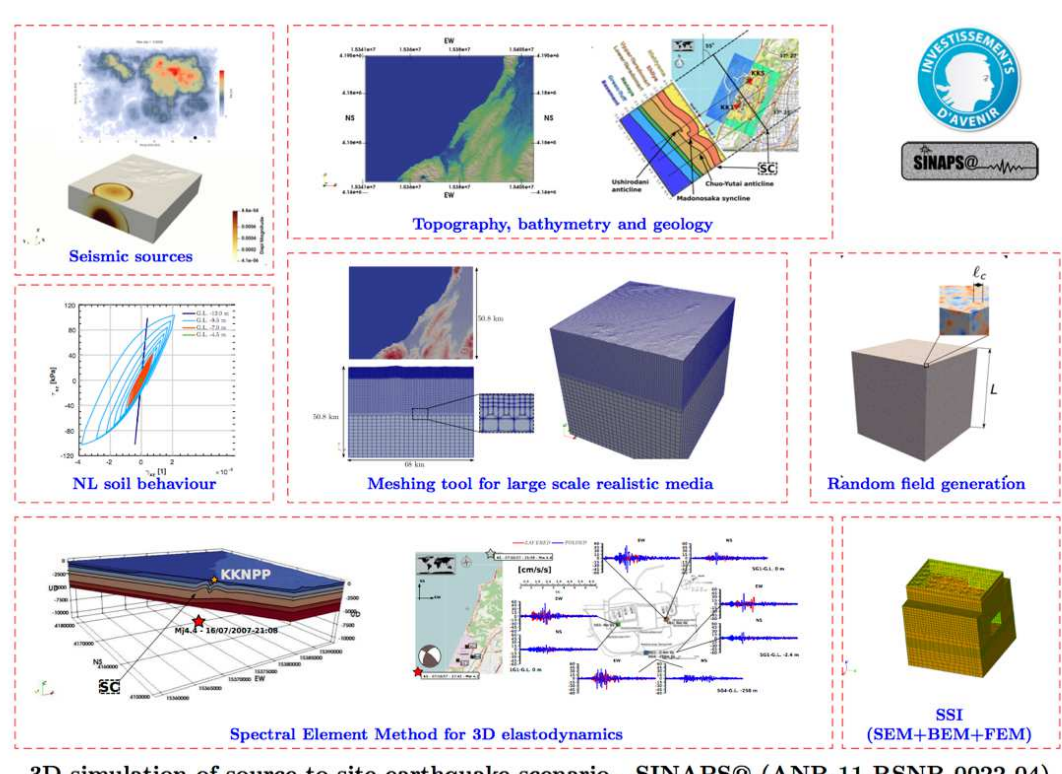

3D simulation of source-to-site earthquake scenario - SINAPS@ (ANR-11-RSNR-0022-04)

Fig. 5: Construction steps of a 3D numerical model to simulate earthquake scenarios from the source to the site using the SEM3D code.

4.1 Numerical solver based on Spectral Elements Method

Solid medium is modelled by the local movement equation linking the displacement $u$, the stress $\sigma$ and the volume forces:

$$
\rho \frac{\partial u}{\partial t^{2}}=\operatorname{div}(\sigma)+f
$$

with $\sigma=C: D u$, where $C$ is the elastic tensor of order 4 and $D u$ is the displacement gradient. Fluid medium is modelled by using the inviscid and potential flow assumptions leading to the following equation:

$$
\begin{aligned}
\frac{1}{k} \frac{\partial^{2}(\rho \phi)}{\partial t^{2}} & =\operatorname{div}(v)+f \\
v & =\frac{1}{\rho} \nabla(\rho \phi)
\end{aligned}
$$

where $v$ is the velocity field, $\rho$ is the density, $\phi$ a scalar potential and $f$ the volume forces.

The discrete weak formulations (using the basis of Lagrange polynomials) of these equations are semi discretized using the finite element method on structured hexahedral meshes for which the element degrees of liberty are 
the Gauss-Lobatto Legendre points. The semi-discrete system to solve is the following:

$$
M_{i j} \frac{\partial^{2} u_{j}}{\partial t^{2}}+F^{i n t}\left(u_{i}\right)=F_{i}^{e x t}
$$

The coefficients of the mass matrix $M_{i j}$ are evaluated using numerical integral quadrature at Gauss Lobatto-Legendre (GLL) points of every elements, allowing the elementary mass matrix to be diagonal and so the global mass matrix to be sparse. The studied time duration is discretized in small intervals $\Delta t$. Are called $u_{n}, v_{n}$ and $a_{n}$ respectively the displacement, velocity and acceleration at the time $t_{n}$.

The temporal evolution of the solution is obtained using the following temporal integration scheme involving three parameters $(\alpha, \beta, \gamma) \in[0 ; 1]^{3}$ at time $t_{n+\alpha}$ (Komatitsch, 1997):

$$
\begin{aligned}
\frac{1}{\Delta t} M\left[v_{n+1}-v_{n}\right]= & F_{n+\alpha}^{e x t}-F^{i n t}\left(u_{n+\alpha}, v_{n+1}\right) \\
u_{n+\alpha}= & \alpha u_{n+1}+(1-\alpha) u_{n} \\
F_{n+\alpha}^{e x t}= & \alpha F^{e x t}+(1-\alpha) F_{n+1}^{e x t} \\
u_{n+1}= & u_{n}+\Delta t\left[\left(1-\frac{\beta}{\gamma}\right) v_{n}+\frac{\beta}{\gamma} v_{n+1}\right] \\
& +\Delta t^{2}\left(\frac{1}{2}-\frac{\beta}{\gamma}\right) a_{n} \\
a_{n+1}= & \frac{1}{\gamma \Delta t}\left[v_{n+1}-v_{n}\right]+\left(1-\frac{\beta}{\gamma}\right)
\end{aligned}
$$

The set of parameters $\alpha=\frac{\beta}{\gamma}=\frac{1}{2}$ has been demonstrated to conserve energy and linear and angular momentums (Simo, 1992). This set of parameters have been chosen for the simulations presented in the following. The time step $\Delta t$ is computed using the Courant's number $C<1$ following:

$$
\Delta t=C \frac{\min \Delta x_{G L L}}{V_{\max }}
$$

where $\min \Delta x_{G L L}$ is the minimum distance between two GLL points and $V_{\max }$ is the maximum propagation velocity of the medium.

Concerning both the lateral and bottom boundary conditions of the model, some spurious waves can appear due to the reflected waves. Thus, so as to simulate open infinite media at boundaries of the domain, Perfectly Matched Layer (PML) are used (Figure 6). Waves amplitudes are damped exponentially when entering into the PML region that are disposed on boundaries modelling an open infinite medium. For example, for a PML disposed on a boundary perpendicular to the $x$ direction, a plane wave:

$$
\phi(x, y, z, t)=A \exp \left(i\left(\omega t-k_{x} x-k_{y} y-k_{z} z\right)\right)
$$


is transformed into : $\tilde{\phi}(x, y, z, t)=\phi(x, y, z, t) e^{-\frac{k_{x}}{\omega} \Sigma(x)}$

where $\Sigma(x)$ is a function that grows exponentially from the interface with the physical medium to the external boundary of the PML region (Berenger, 1994; Festa and Vilotte, 2005).

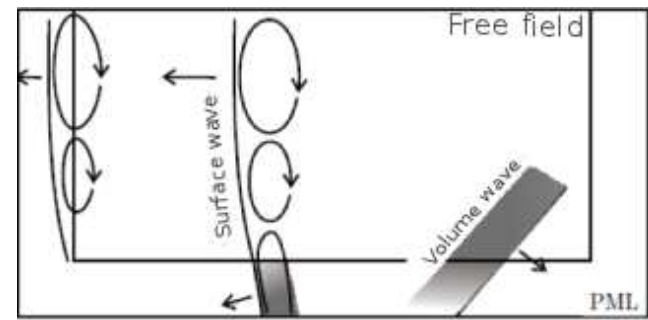

Fig. 6: A simple schema of a numerical domain for the elastic waves propagation in the presence of a free surface and PML. A volume wave is always attenuated by penetrating a PML. Surface waves decrease exponentially when they enter lateral PML, but the attenuation disappears when they penetrate the lower PML.

\subsection{Mesh construction}

In this study, in order to consider the real topography and bathymetry of the studied site, a mesh tool (HexMesh) was used to generate the Argostoli model (Figure 7). It is a software tailored to extrude a given Digital Elevation Model (DEM) down to a certain depth so to obtain an unstructured hexahedral mesh. HexMesh $^{1}$ is a hexahedral mesh generator for large domains based on octree and 27-tree structures. It allows for consideration of topography, bathymetry and coastlines, as well as water bodies and basins for geophysical applications. Moreover, this code allows the construction of a mesh more refined at the top.

\subsection{Seismic source}

In this work the seismic source was modelled by point-wise double-couple located at $14 \mathrm{~km}$ depth. The function describing the time evolution of the displacement offset used is the source model proposed by (Brune, 1970), expressed by the equation 12 where $t_{s}$ is the time-shift ans $\tau$ is the rise time. Figure 8 displays the obtained time-history velocity and the Fourier spectra at the source. It represents a magnitude $\mathrm{M}_{w} 4.6$ with Strike $=163^{\circ}$, Dip $=39^{\circ}$, $\mathrm{Slip}=92^{\circ}$ (Figure 9 shows a snapshot of the seismic wave propagation). More

1 Source: https://github.com/jcamata/HexMesh.git 

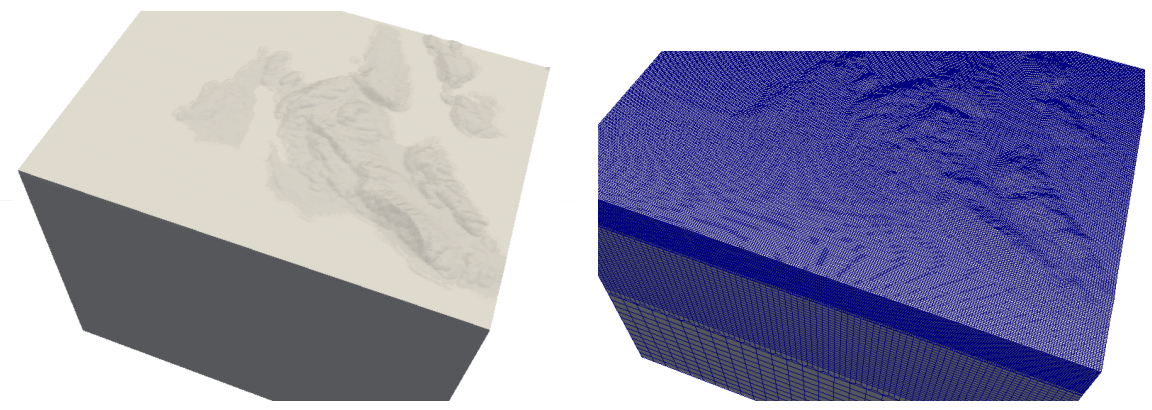

Fig. 7: Sketch of (left) numerical model including topography and bathymetry built using HexMesh (right) mesh of the model using HexMesh

detailed information about the data used to model the point source (orientation, magnitude) are available through the GEOFON Program website:

https://geofon.gfz-potsdam.de/data/alerts/2016/gfz2016kylx/mt.txt

$$
f(t)=1-\left(1+\frac{t-t_{s}}{\tau}\right) \exp \left(-\frac{t-t_{s}}{\tau}\right)
$$

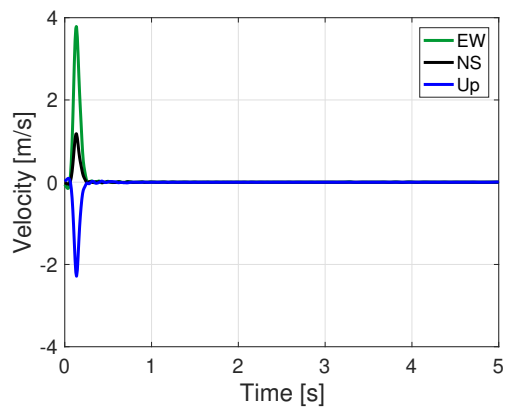

(a)

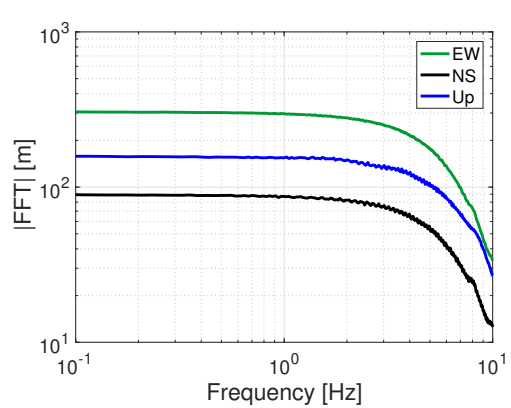

(b)

Fig. 8: (a) Time evolution of the source velocity function used for a double couple point source in SEM3D.(b) Fourier spectra of the used source velocity function for the simulation. 


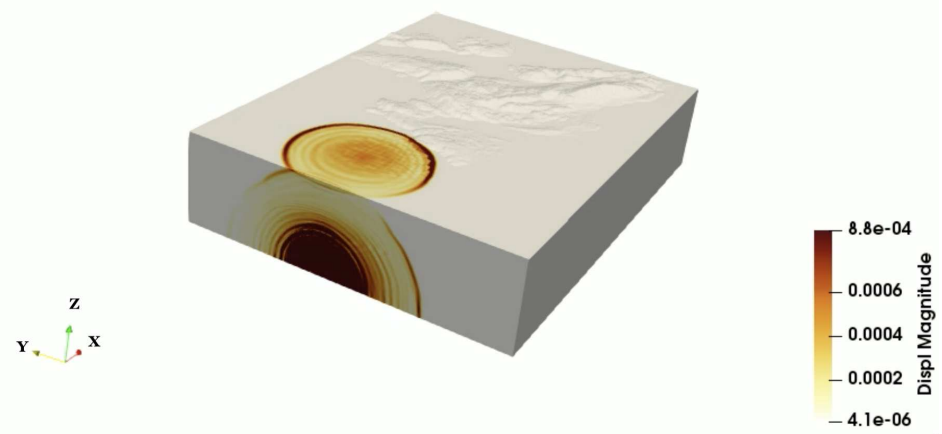

Fig. 9: Snapshot of seismic source modelled by a point-wise double-couple of a magnitude $\mathrm{M}_{w} 4.6$ located at $14 \mathrm{~km}$ depth.

\section{Simulations}

In this section are presented the studies that were conducted in order to evaluate the effect of two aspects on the obtained ground motion:

- The topography and bathymetry

- The Argostoli basin

It is important to note that only for the first aspect the real seismic event introduced previously in Subsection 4.3 was simulated. However, for the second aspect (effect of Argostoli sedimentary basin), the same parameters of the seismic event have been adopted but the source location has been changed. This is due to the size of the domain of interest that has been restricted in order to well represent the sedimentary area. No real earthquakes were recorded (in the available database) in this restricted area. As a result, the analyses of local geology effect will not be compared to recorded data. However, the comparisons will be limited to measured trends for some quantity.

The main objective of the following section is to highlight the importance to consider the whole geological configuration of an area for seismic risk analysis compared to a using traditional layered models.

\subsection{Topography and bathymetry effect}

The characterization and consideration of site's effects, related to soil conditions, are essential for the evaluation of seismic risk. Topographic features and sedimentary fill are part of these observed site effects. This work focuses on this type of local effect. In order to quantify the influence that the consideration of real topography and bathymetry of the site could have on its seismic response, three numerical models have been studied and compared. The models have the same size: $67 \times 50 \times 50 \mathrm{~km}$. The first case is a layered model that does 
not take into account topography or bathymetry (Figure 10.a). The numerical code used in this study to perform numerical simulations was validated with a semi-analytical method (Hisada, 1994, 1995, 2008) using Green's functions (O'Connell et al., 2012) for horizontally layered half spaces (Gatti, 2017). The size of the elements constituting the mesh is $320 \times 320 \mathrm{~m}$ in the horizontal directions (EW and NS) and 250m vertically in the first layer of soil. The size of the elements in the vertical direction is adapted to propagate the desired frequency band according to the properties of the soil layers. The total number of elements of this model is 1.8 millions. The second case is built with the same velocity profile (i.e. stratigraphy) but it takes into account the topography of the site (Figure 10.b). The third model include the real geometry of the soil surface: topography and bathymetry (Figure 10.c). The presence of seawater is also taken into account by modelling it with a fluid with a density of 1.03 $\mathrm{g} / \mathrm{cm}^{3}$ and a $\mathrm{P}$ wave propagation velocity equal to $1.5 \mathrm{~km} / \mathrm{s}$. It must be noted that the topography of the region is very marked. Indeed, the altitude of the hilly areas is up to $1600 \mathrm{~m}$ (Figure 11). The size of elements for this case is $280 \times 200 \times 207 \mathrm{~m}$. The total number of elements for this model is close to 2 millions. All the obtained signals have a baseline correction and they are filtered using a non-causal fourth-order Butter-worth bandpass filter (i.e., zero-phase digital filtering), between 0.15 and $8 \mathrm{~Hz}$.

Figure 12 shows the study site as well as the locations where the sensors (numerical) were placed. In order to highlight the influence of topography and bathymetry on the prediction of ground motion, a comparison of accelerograms was carried out at the four stations shown in this figure.

\subsection{Basin effect}

Concerning the local geology, in order to evaluate the effect of the sedimentary basin on ground motion, three different models have been studied and compared (Figure 13). This work is based on a first, less detailed, study that was carried out in Touhami et al. (2019). Once again, the three models have the same size: $27 \times 30 \times 50 \mathrm{~km}$ (Figure 14). The size of the elements constituting the mesh is $130 \times 130 \mathrm{~m}$ in the horizontal directions (EW and NS). For the vertical direction the size of the elements is adapted according to the properties of each layer. The built mesh allows propagation of frequencies up to 7 $\mathrm{Hz}$ for a minimum shear wave velocity of $650 \mathrm{~m} / \mathrm{s}$. All the obtained signals have a baseline correction and they are filtered using a non-causal fourth-order Butterworth bandpass filter (i.e., zero-phase digital filtering), between 0.1 and $7 \mathrm{~Hz}$. The mesh is built independently from the geological properties. Then the properties are given by Cushing et al. (2019) are interpolated on the GLL points of the already constructed mesh using a not-honouring strategy. In this work, as a first approach a coarse geological resolution of $100 \mathrm{~m}$ has been used even if we have access to a geological resolution of $10 \mathrm{~m}$. The influence of mesh element size, geological resolution, mechanical properties and maximal propagated frequency (wave length) have not been investigated in this paper and will 


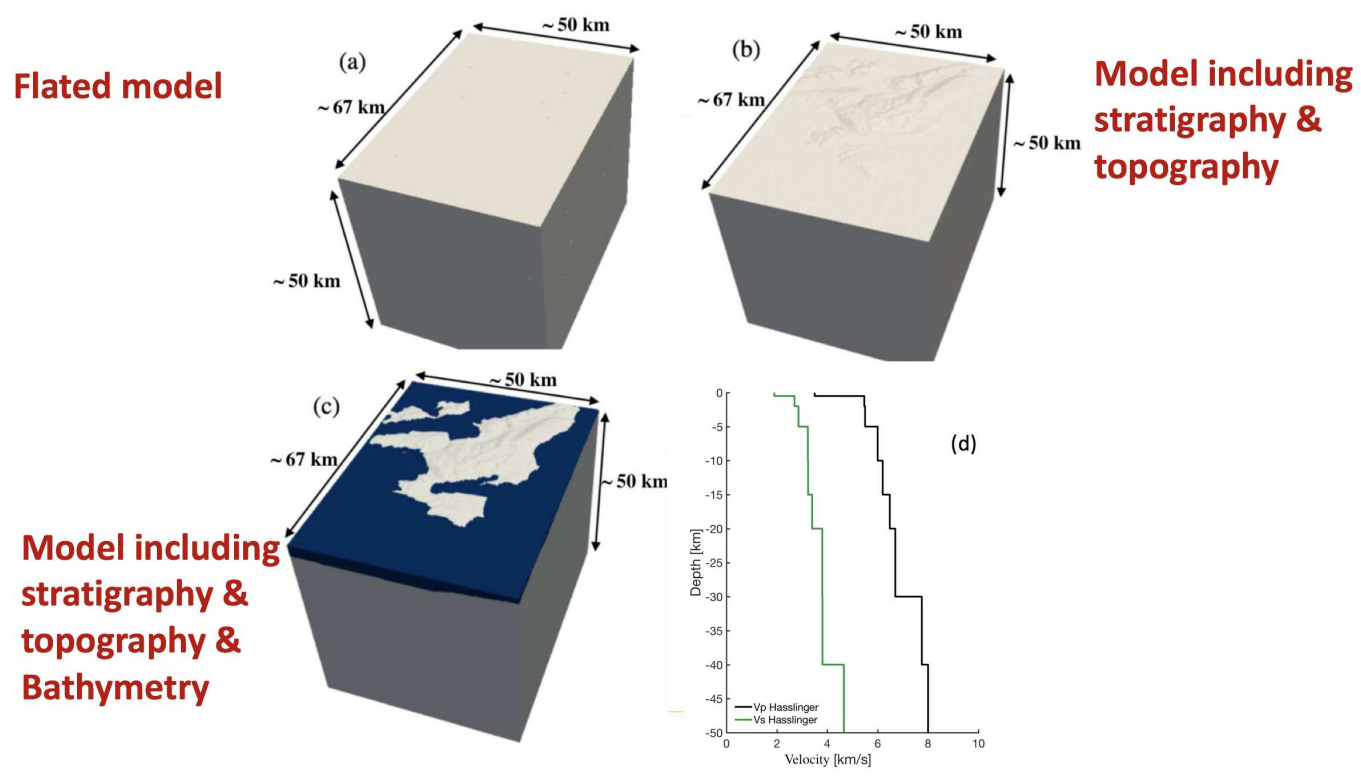

Fig. 10: Studied cases: (a) Layered model. (b) Model including stratigraphy, topography. (c) Model including stratigraphy, topography and bathymetry. (d) 1-D bedrock velocity profile used in all models.

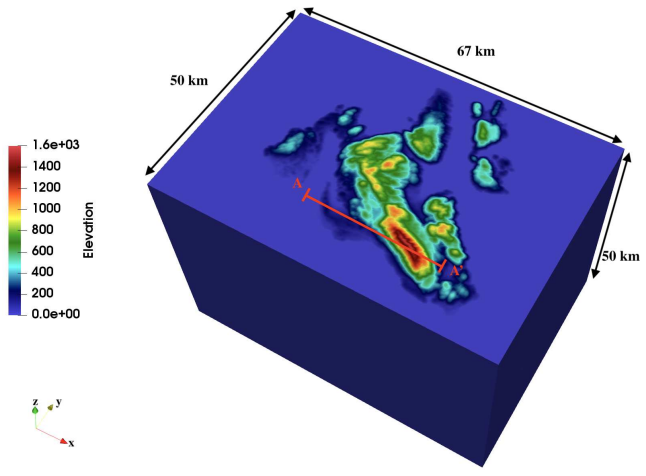

(a)

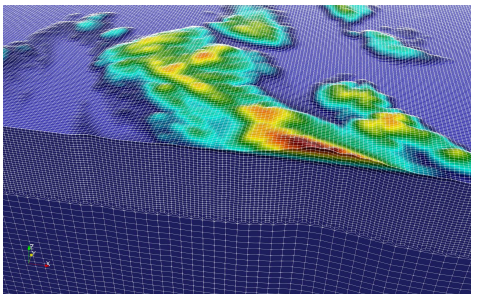

(b)

Fig. 11: (a) Scheme of the elevation map of the studied model.(b) The crosssection A-A'.

be studied in a future work. Some authors have studied similar topics. Kristek et al. (2018) presented a methodology of calculating earthquake ground motion characteristics at a site of interest (including sedimentary basins for example) assuming acceleration at a reference site (homogeneous halfspace). Other numerical studies focus on the effects of subsurface geometry on seismic 


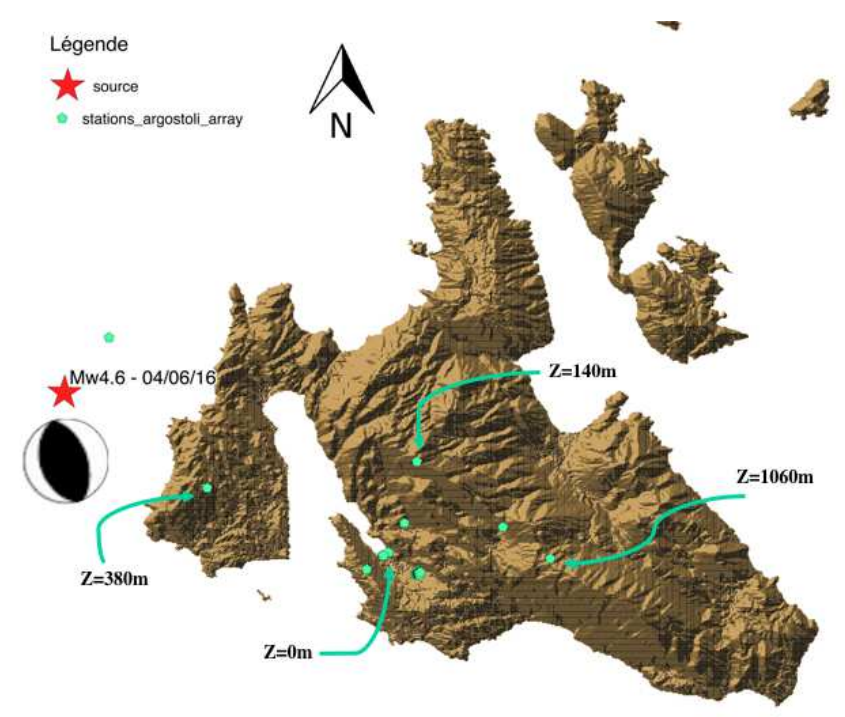

Fig. 12: Studied area. The green points correspond to the location of the sensors in the numerical models. $\mathrm{Z}$ is the altitude of each sensor

ground motion by investigating the sensitivity of $2 \mathrm{D} / 3 \mathrm{D}$ basin seismic response to parameters related to the geometry of the basin (Riga et al., 2016; MezaFajardo et al., 2016). A study performed by Volpini and Douglas (2019) on geometries that are in between these two models (flat parallel soil layers and (steep valleys, canyons and basins), such as sites with gently dipping layers.

The first case is a layered model using the velocity model proposed by Haslinger et al. (1999) (for upper layers). However, this model does not allow for the local effects. For the second case, the lower interface of the Argostoli basin was considered with stratified layers inside the basin. Finally, to take into account the geological characteristics of the site, a more refined model has been studied considering the real geometry of the sedimentary fills (Figure 15). 


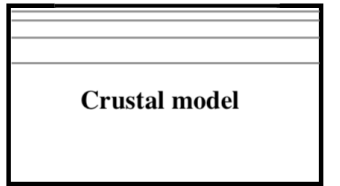

(a) Model layered

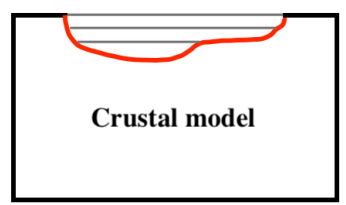

(b) Model V1

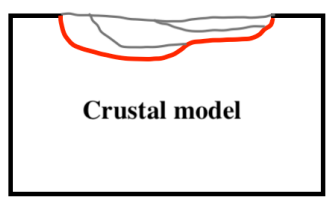

(c) Model V2

Fig. 13: Studied cases to evaluate basin effect on seismic ground motion. (a) The first model is a layered one. (b)For the second model the lower layer of local geology is considered with stratified layers inside. (c) The last studied model takes into account the identified local geology of the studied site.

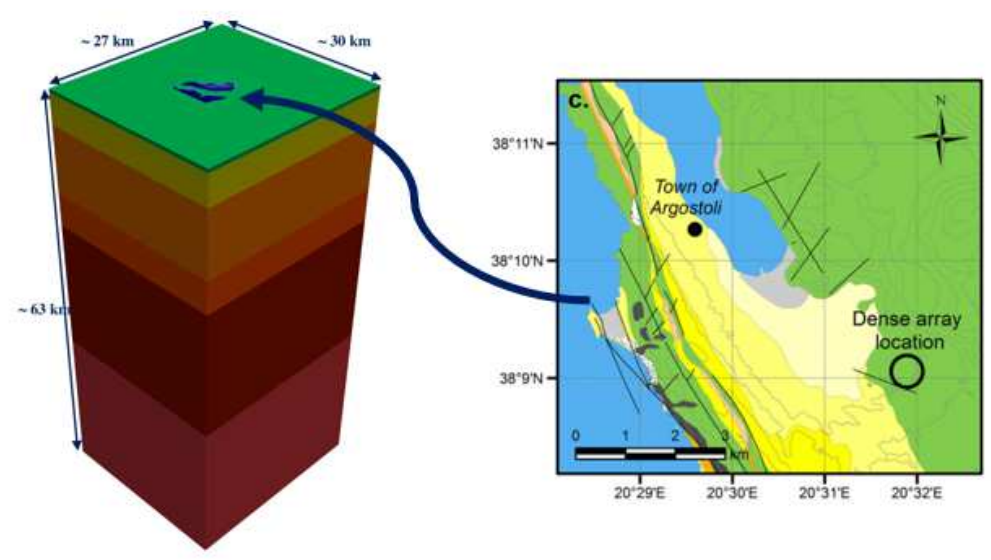

Fig. 14: Sketch of the studied Argostoli area including basin model. 

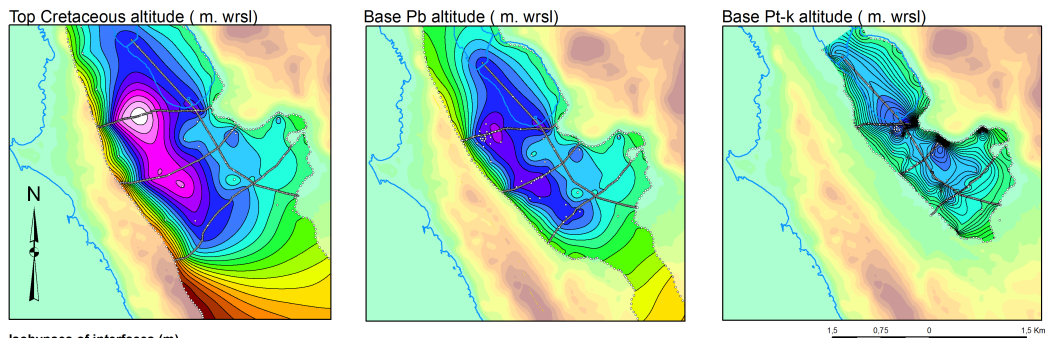

$x^{2}$

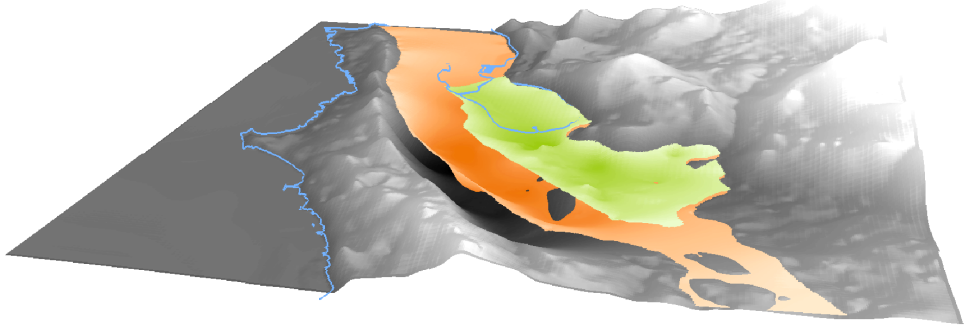

Fig. 15: Studied area. 3D refined geological model of Argostoli region ias proposed by Cushing et al. (2019). The three top figures describe the identified three geological layers and their altitude. The bottom figure shows a $3 \mathrm{D}$ view of these three geological layers. 


\section{Results}

After presenting the numerical tools used and the simulations performed, the analysis of geology effects are discussed in this part. First, the effect of topography and bathymetry are shown by comparing the studied models for i) time history acceleration, ii) Fourier spectra and iii) amplification function (AF). A comparison with the recorded data has been carried out. In a second part, the effect of the sedimentary basin of Argostoli is evaluated by analysing three quantities : time-history acceleration, amplification function and sensors displacement. As indicated before, for this case no comparison with recorded data is performed due to the restricted zone of study.

\subsection{Effect of global geology}

\subsubsection{Topography effect}

Several theoretical and numerical studies have been conducted to better understand the influence of topography on the propagation of seismic waves (Bouchon, 1985; Geli et al., 1988; Komatitsch and Vilotte, 1998; Zhou and Chen, 2006). It is generally observed that the recorded movements at the summits of the hilly areas are greater than those recorded at their base. This amplification corresponds to a concentration of energy related to the reflection of the incident waves towards the interior of the structure. The theoretical and experimental results are generally in good agreement qualitatively, but the level of the calculated amplifications often underestimates the observed amplifications. Different explanations have been put forward to explain such differences. 2D modeling may initially be too limited for the evaluation of such effects generated by a very irregular topography or involving a combination of hills. Experiments at the site where strong accelerations were recorded during the Northridge earthquake revealed the 3D nature of the seismic response of the hill (Spudich et al., 1996). Numerical simulations taking into account 3D structures have shown particularly important directional effects (Bouchon and Barker, 1996; Bouchon et al., 1996).

Figure 16 shows the comparison between simulated signals obtained at different points and different altitudes for the model considering topography (magenta line) and accelerograms obtained at the ground level for the other one (green line). The comparison were made for both time-history acceleration and Fourier spectra. For Fourier spectra a smooth Konno Ohmachi function with a bandwidth coefficient equal to 40 was used. A slightly shifted wave arrival is noted when the topography is taken into account. A different deamplification level depending on the location of the sensors is also observed for the model with topography. Indeed, for the three simulated signals at the top of the hill, a difference with the case without topography is noticed, nevertheless it could be neglected. On the other hand, the comparison between the two models for points at the ground level (having the same coordinates but 
different altitudes) shows a significant differences (Figure 16a and 16b): the presence of the topography de-amplifies widely the site response. It is noted that the topography enrich the frequencies. These results are overall in good agreement with existing works except for the case at $\mathrm{z}=1060 \mathrm{~m}$ (Figure $16 \mathrm{~g}$ and $16 \mathrm{~h})$ altitude where topographic amplification was expected. Hence, it can be observed that these amplification phenomena show a great spatial variability, induced by the irregularity of the topography and the incident waves.

Indeed, it has been found that the maximum amplification can occur in a concentrated area near the summit, or can take place at the halfway up the hill while the summit has a de-amplification (Komatitsch and Vilotte, 1998). This highlights the complexity of this purely geometric phenomenon which can reveal interactions between the waves propagation and the irregularities of the surface topography.

\subsubsection{Bathymetry effect}

The analysis here is focused mainly on the difference between the model including topography only and the one including topography as well as bathymetry. Figure 17 shows the comparison of the time history acceleration and the Fourier spectra of the two case studies at the same previous stations.

It is noted that for stations located far from the sea at high altitudes (380 and $1060 \mathrm{~m}$ ), the seismic response of the soil is the same for both models including topography. As expected, the closer sensors are to the coast, the more the presence of bathymetry affects the seismic response of the soil. On the other hand, these graphs show that the consideration of the bathymetry especially has the impact of amplifying the ground motion.

In order to highlight the importance of amplification, the amplification spectral ratio between the topography\&bathymetry model and layered model has been plotted in Figure 18. This ratio is defined as the ratio between the geometric average of the Fourier amplitude spectra of the horizontal components at the surface and the downhole (rock) (Castro Cruz, 2018):

$$
B S R=\sqrt{\frac{E W_{\text {surf }}^{2}+N S_{\text {surf }}^{2}}{E W_{\text {rock }}^{2}+N S_{\text {rock }}^{2}}}
$$

It can be observed that the amplification is significant, especially at stations located at high altitude for lower frequencies.

\subsubsection{Comparison with recorded data}

In this section, a comparison between simulated accelerograms for the numerical model including topography and bathymetry and those recorded at the site is carried out (Figure 19) at four stations having the same coordinates but at different depths (83, 40,15 and 0 meters deep). These sensors are all located in the sedimentary basin (Figure 20). 
The accelerograms computed in the 'topography \& bathymetry case' at depth $83 \mathrm{~m}, 40 \mathrm{~m}$ and $15 \mathrm{~m}(19 \mathrm{~g}, 19 \mathrm{e}, 19 \mathrm{c})$ are very similar to the recorded ones. However, at free surface, the recorded motion is larger than the simulated one accounting for the topography and bathymetry. This may be due to the fact that the sedimentary formations have not been modelled and therefore the site effects have been neglected. On the other hand, the Fourier spectra of the four stations show that some frequencies (1.8 and between 3 and $4 \mathrm{~Hz}$ ) are not captured by the numerical model. As shown in the next section, these frequencies correspond to the fundamental frequencies of the basin (Theodoulidis et al., 2018). Therefore, the missing of geological structure of the koutavos sedimentary basin from the numerical model is most probably the reason for this difference between measurements and simulations.

This results indicate that the layered model is probably too simplistic. Indeed, there is always an area with lower wave propagation velocity which combined with the topographic effect create larger amplifications. Hence detailed modelling of the sedimentary basin including spatial variability has to be carried out.

\subsection{Effect of local geology}

It is known that loose soil deposits tend to concentrate damages caused by an earthquake. These damages are characterized by a strong variations and amplification of ground motion. The objective here is to study the effect of this geometrical shape on ground motion prediction.

It has been observed that for the point 7 the obtained signals in the axes EW and NS are not orthogonal (i.e. they are correlated). It means that they are not in the same direction of the principal directions of the wave propagation. However, for the Point 6, both signals (EW and NS) are uncorrelated in the layered case. In addition, It is well known that for an earthquake ground motion signals recorded at any sensor, the position of source point can be found by determining the angle $\phi$ for which the correlation coefficient between the two horizontal components is equal to zero (Rezaeian and Der Kiureghian (2012); Svay et al. (2017)). Thus, so as to compare the obtained response between both points, the uncorrelated signals for point 7 are the ones for an angle $\phi$ equal to 10 which corresponds to principal direction of the wave propagation. Hence, the horizontal components of Point 7 have been rotated by $\phi$ equal to 10 . Figure 21 presents a comparison of the time-history accelerations computed at same station but at different depths (83, 40, 15 and 0 meters deep). It is noted that the greater the depth, the less amplified the motion is for both models including the sedimentary basin. Indeed, it can be noticed that for the case of the layered model, the acceleration level remains constant at the four depths. On the contrary, for the other two cases, the motion is stronger at the surface as compared to deeper sensors.

An analysis of the seismic response in a borehole located in the basin, which corresponds to the one performed by the experimental team, is done. 
The results are given in three stations noted P7, P6 and P3 corresponding respectively to CKWP, CK0 and CK83 mentioned in Figure 20. Figures 22a, $22 \mathrm{~b}$ and $22 \mathrm{c}$ illustrate the acceleration time history at the three points. As expected, the acceleration inside the basin at the surface is amplified. another aspect noted is the elongation of signal duration at the surface of the basin compared to the other two stations. In Figure 22d are plotted in blue and red the amplification spectral ratio. Two peaks at approximately $1.8 \mathrm{~Hz}$ and between 3 and $4 \mathrm{~Hz}$ are present for both $\mathrm{P} 6 / \mathrm{P} 3$ and $\mathrm{P} 6 / \mathrm{P} 7$ amplification ratio. These frequencies correspond to the resonance frequencies of the Argostoli basin observed by Theodoulidis et al. (2018). Another peak observed at 0.3 $\mathrm{Hz}$ on the blue curve that could be due to the simplification assumptions (i.e. velocity profile). The comparison of the simulated results with the black curves that represent the standard spectral ratio (SSR) analysis of recorded events in the studied site performed by Perron et al. (2018b) shows that the same amplification level is obtained. In high frequencies, almost the same peaks with the same level of amplification are observed. However, in low frequency ( 1.8 $\mathrm{Hz}$ ) the same peak but with a lower amplitude is found. This is probably due to the simplification of the chosen velocity profile or the depth of the source.

Now concerning the particle displacement at the surface, Figure 23 shows, for the three studied models, the vertical displacement as a function of the horizontal displacement (in the two directions $\mathrm{x}$ and $\mathrm{y}$ ) of the two points of interest. It is noted that in the case of the layered model the vertical motion of particles is very small. In the two other cases this displacement is more important especially at the point inside the basin (point 6). The realistic geometry of the basin (Basin V2) generates a stronger displacement than the simplified case (Basin V1). This indicates the existence of surface waves due to the presence of the basin. So as to confirm the effect of the presence of the basin on the time elongation at the surface signals, Figure 24 shows some snapshots of the wave-field displacement in the model that illustrate this phenomenon. 

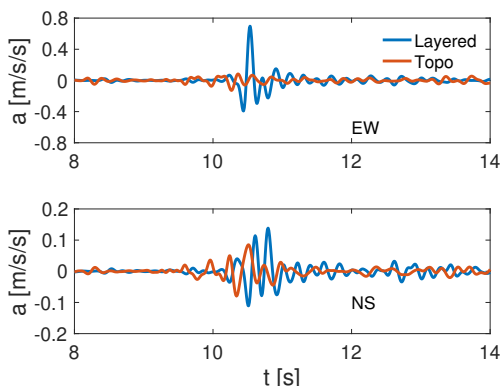

(a)
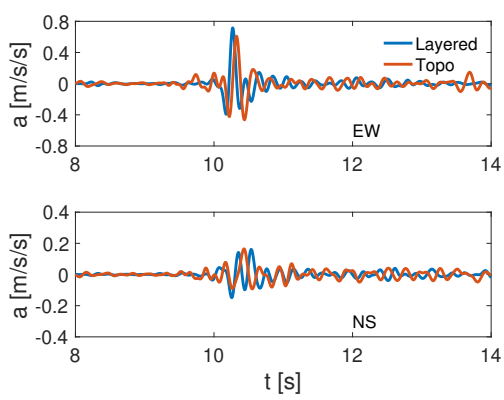

(c)
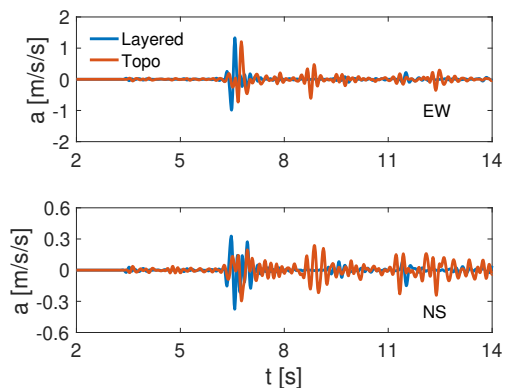

(e)
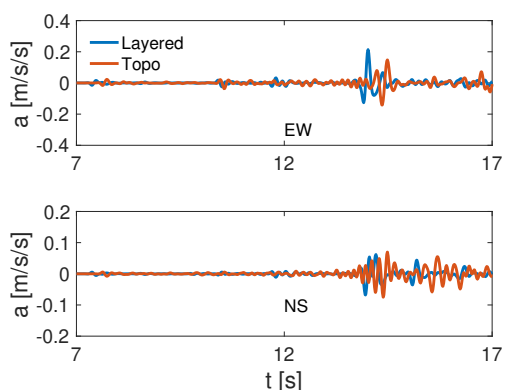

(g)

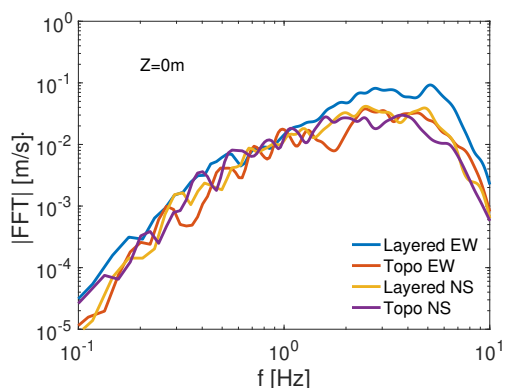

(b)

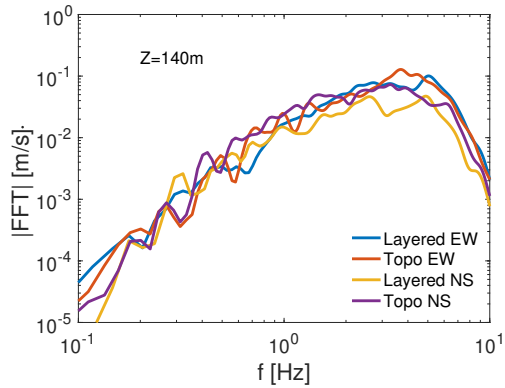

(d)

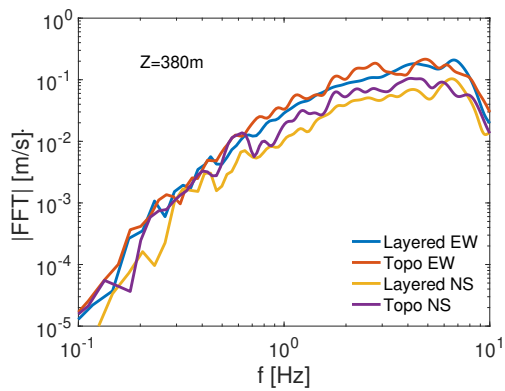

(f)

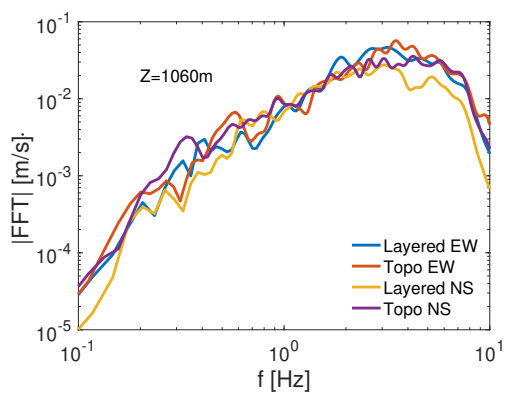

(h)

Fig. 16: Comparison of time history acceleration (a,c,e and g) and Fourier spectra (b,d,f and h) of the layered model and model including topography at the stations described in Figure 12. 

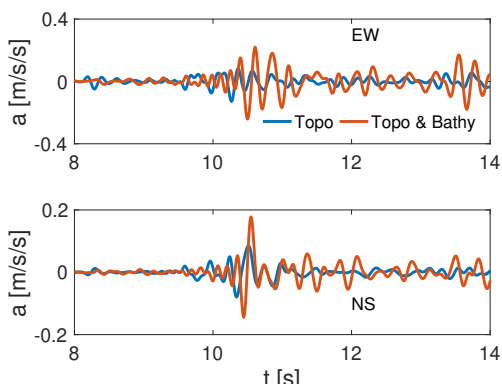

(a)
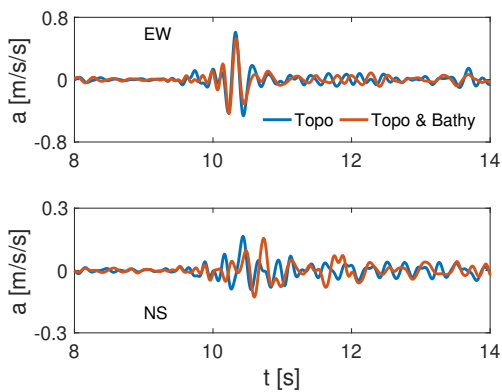

(c)
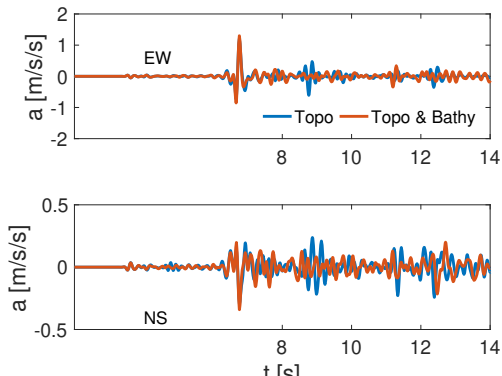

(e)
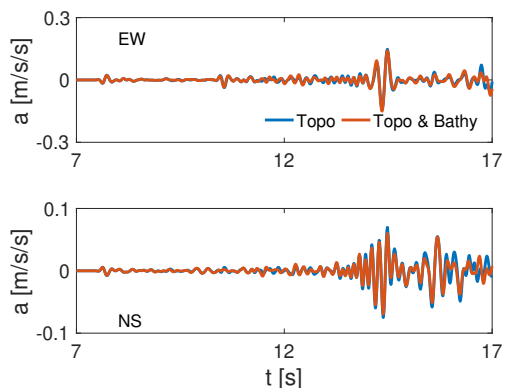

(g)

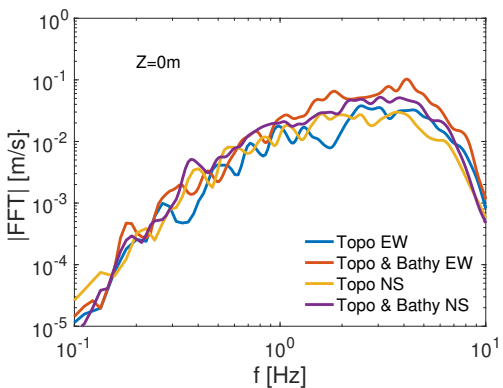

(b)

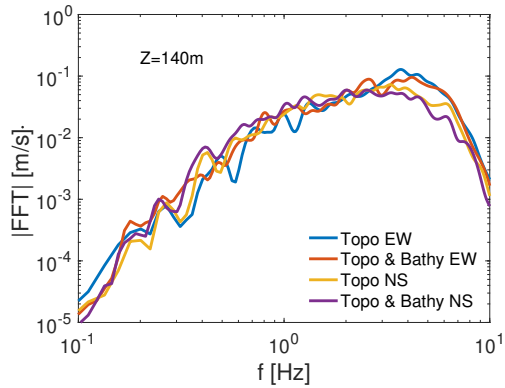

(d)

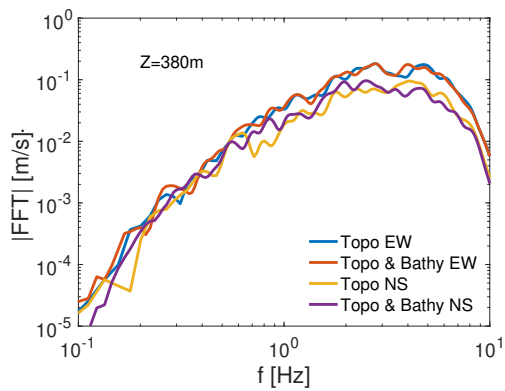

(f)

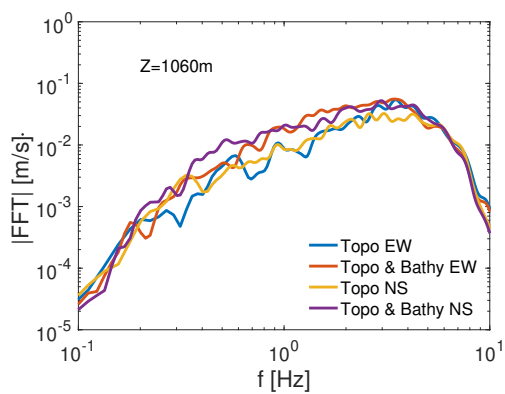

(h)

Fig. 17: Comparison of time history acceleration (a,c,e and g) and Fourier spectra (b,d,f and $h$ ) of the layered model, model including topography and the model including topography and bathymetry at the stations described in Figure 12. 


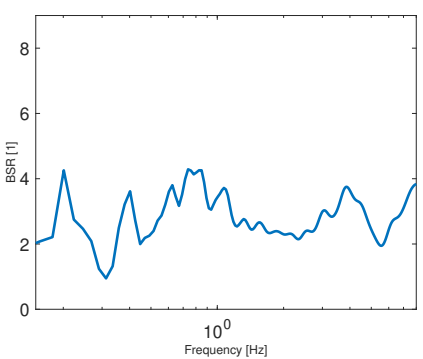

(a) $\mathrm{Z}=0 \mathrm{~m}$

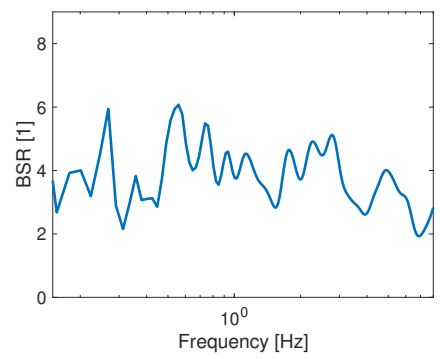

(c) $\mathrm{Z}=380 \mathrm{~m}$

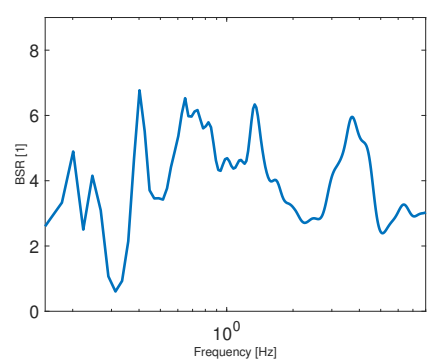

(b) $\mathrm{Z}=140 \mathrm{~m}$

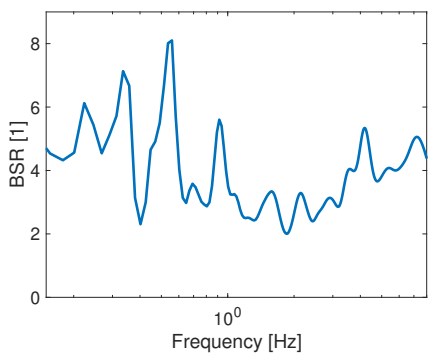

(d) $\mathrm{Z}=1060 \mathrm{~m}$

Fig. 18: Amplification spectral ratio between the model including the topography and bathymetry and the layered model at the four studied stations (Figure 12). 

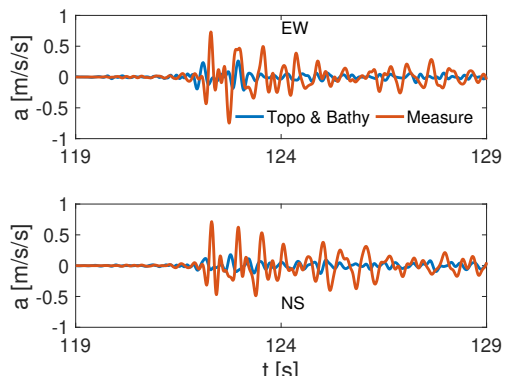

(a)
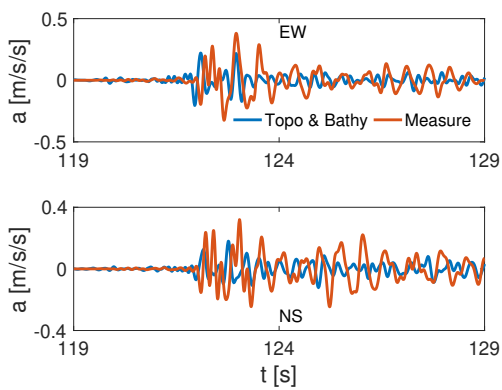

(c)
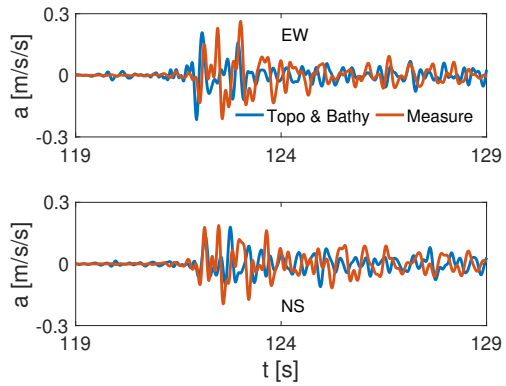

(e)
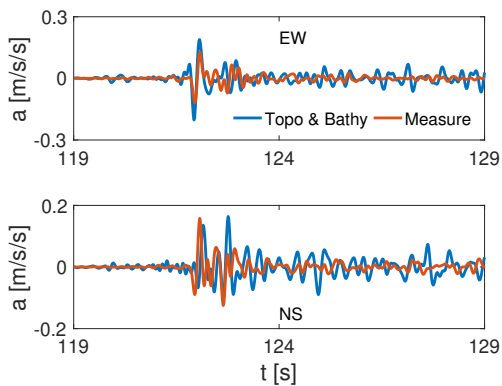

(g)

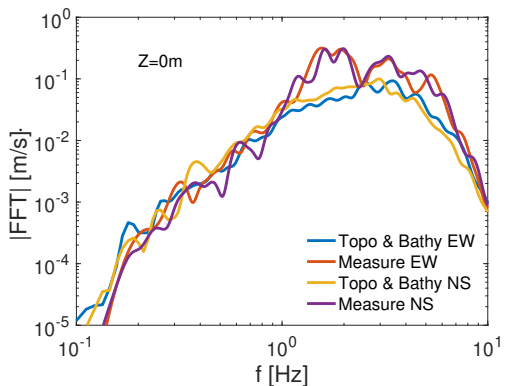

(b)

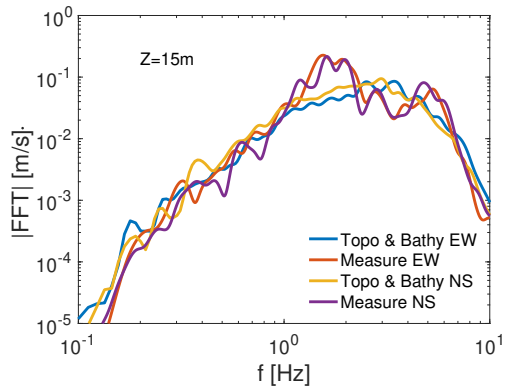

(d)

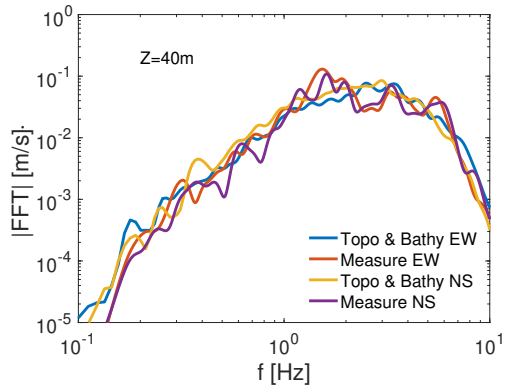

(f)

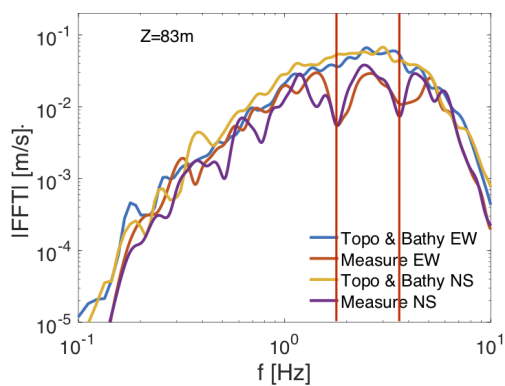

(h)

Fig. 19: Time history comparison of the model including topography and bathymetry with the recorded data at four stations: (a \& b) at the surface, (c \& d) at $15 \mathrm{~m}$ depth, (e \& f) at $40 \mathrm{~m}$ depth and ( $\&$ h) at $83 \mathrm{~m}$ depth. 
(a)

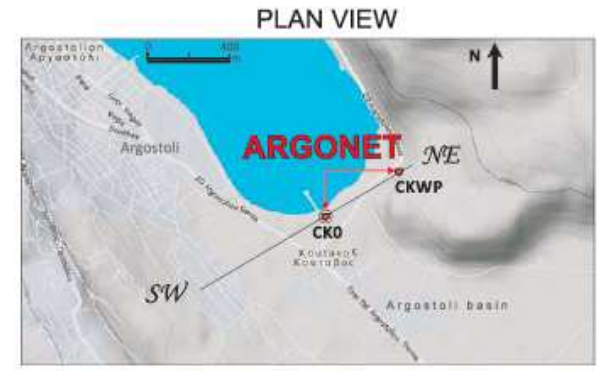

(b)

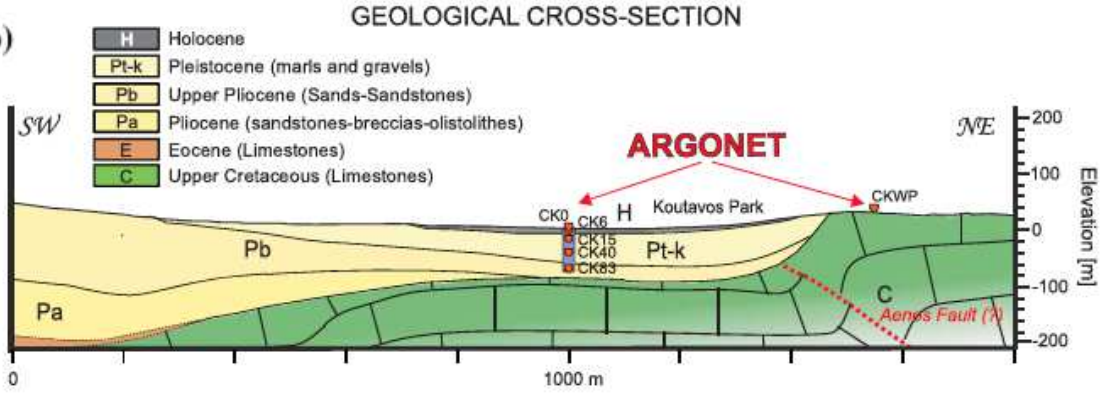

Fig. 20: Basin plan view. Line SW-NE on (a) marks the surface projection of the (d) geological cross section. Location of the registration stations of the Argostoli site are shown on the figure. The four stations are at the same point but at different depths $(0,15,40$ and 83 meters). From Theodoulidis et al. (2018) 


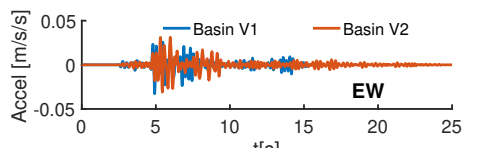

$\mathrm{t}[\mathrm{s}]$

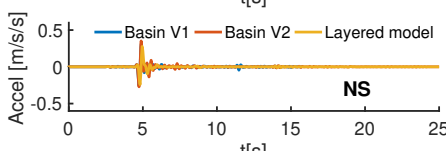

(a)
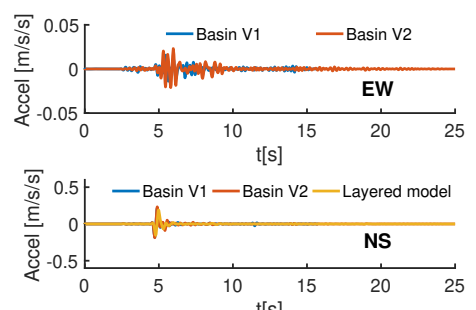

(c)
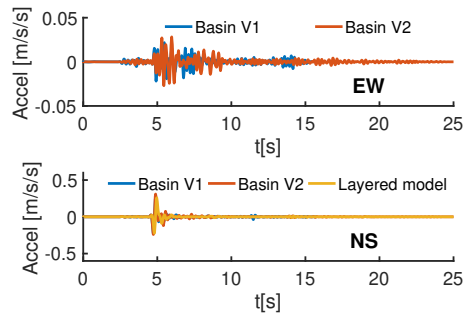

(b)

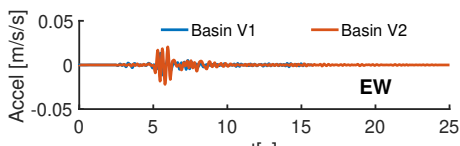

$\mathrm{t}[\mathrm{s}]$

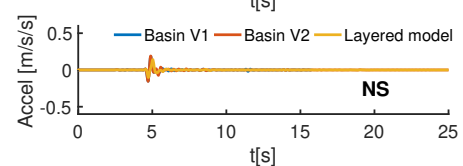

(d)
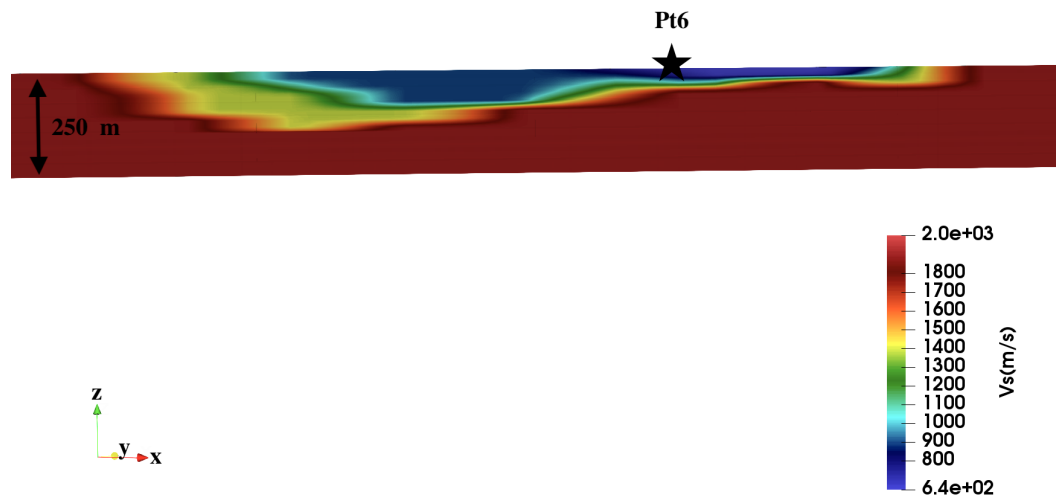

(e)

Sensors localisation

Fig. 21: Comparison of time-history acceleration of the three studied models at four points located at the same place but different depth: (a) at the surface, (b) at $15 \mathrm{~m}$ depth, (c) at $40 \mathrm{~m}$ depth and (d) at $83 \mathrm{~m}$ depth. 


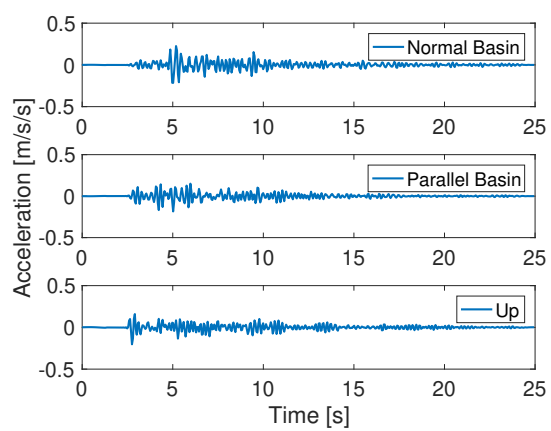

(a) Station P6

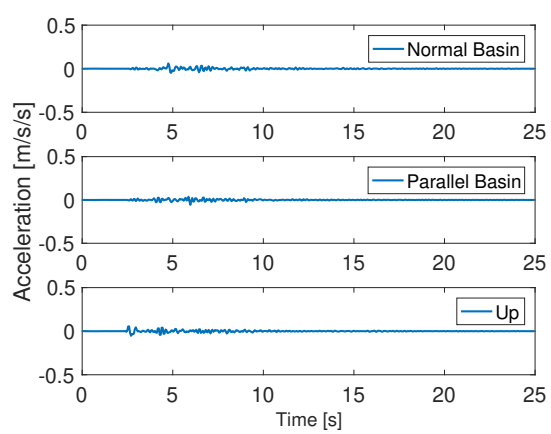

(c) Station P3

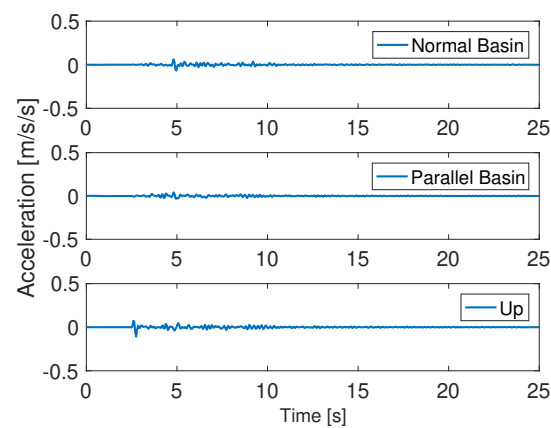

(b) Station P7

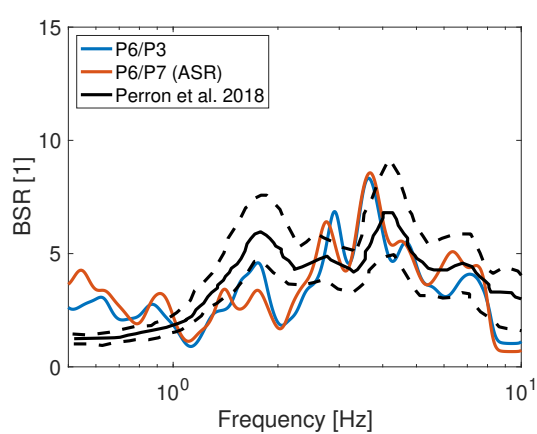

(d) BSR

Fig. 22: Acceleration time history obtained at three points : (a) Basin surface (P6), (b) Rock (P7) and (c) Basin depth (P3). (d) correspond to the amplification spectral ratio between $\mathrm{P} 6 / \mathrm{P} 3$ in blue (basin/outcrop) and $\mathrm{P} 6 / \mathrm{P} 7$ in red (basin/borehole), black curves represent the amplification function calculated from recorder events in Perron et al. (2018b) between stations ACWP (outcrop) and ACIN (basin). 

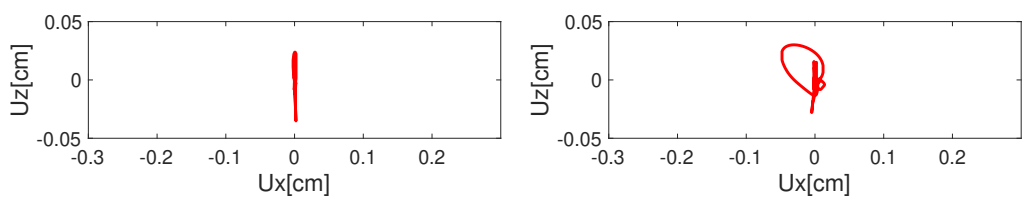

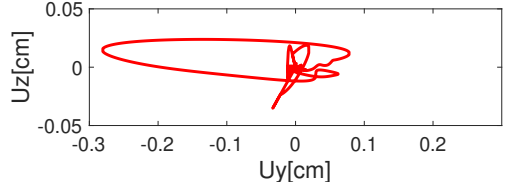

(a)

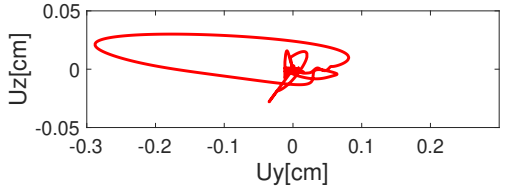

(b)

Layered model
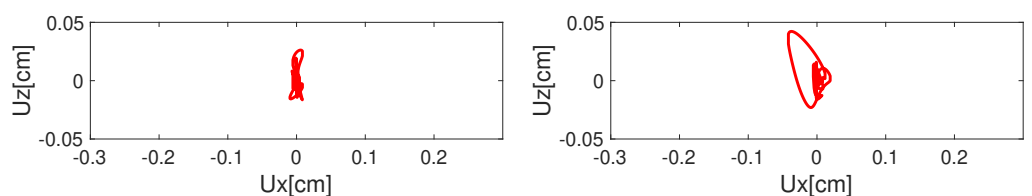

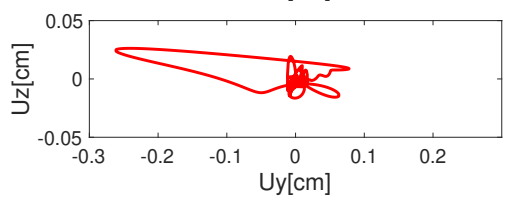

(c)

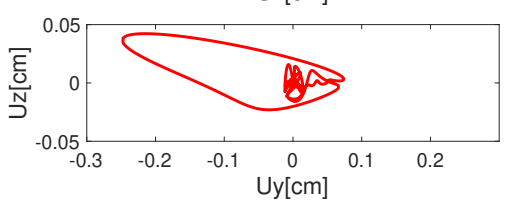

(d)

Bassin V1
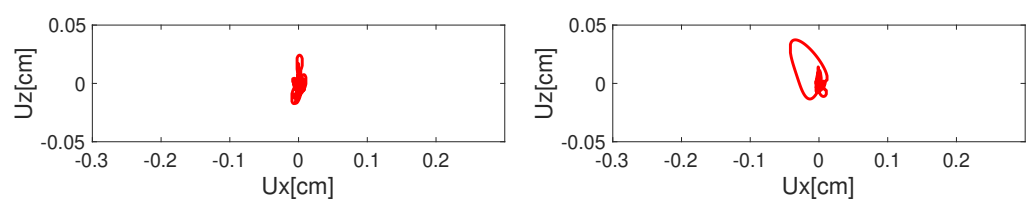

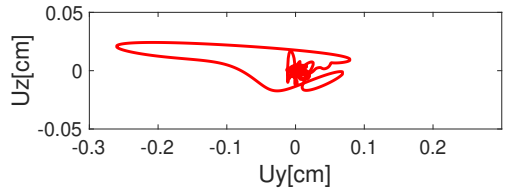

(e)

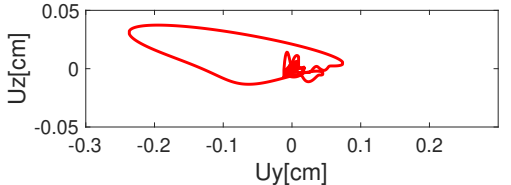

(f)

Bassin V2
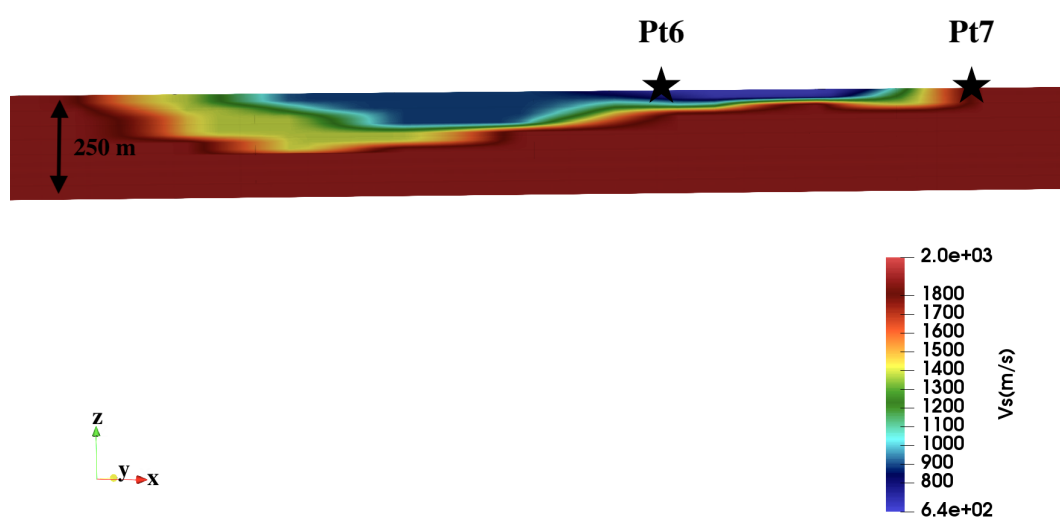

(g) Sensors localisation

Fig. 23: Comparison of sensors displacement for the three studied models : (a), (c), (e) at point 6 located inside the basin and (b), (d), (f) at point 7 located outside the basin. 


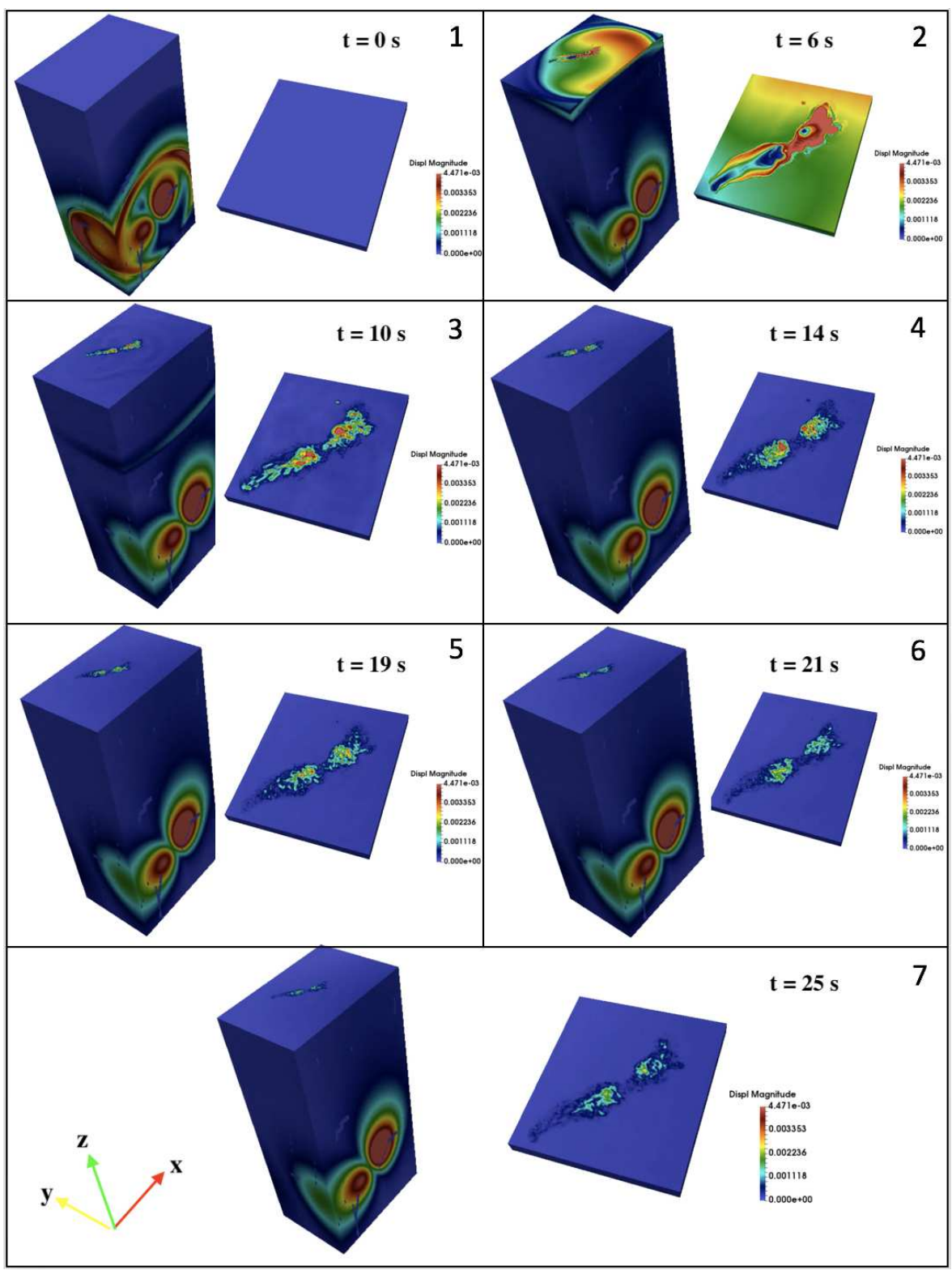

Fig. 24: Snapshots of the wave-field displacement in the basin at different time step non-consecutive. 


\section{Conclusion}

In this paper, numerical tools used to carry out 3-D physics-based analysis are presented. Numerical simulations performed in the Argostoli site highlight the influence of both topography, bathymetry and sedimentary fill on the ground motion prediction. Moreover quantitative rules to account for these effects on the ground motion are not easy to characterise. The presence of a hilly areas can greatly influence the seismic response at a given site, even relatively far from the topographic and bathymetric formations. This first part of the work, which corresponds to the regional model, allowed the validation the built crustal model. Indeed, the comparison of the simulated results with the recorded ones showed a good agreement at deep stations and differences at the surface. This discrepancies are due to absence of the basin modelling because of the size of the model. On the other hand, concerning the smallest model including the basin, it has been shown that sedimentary fill tend to concentrate amplifications and generate surface waves. In fact, considering the real shape of the basin had particularly an effect on the frequency content of the signal as well as the amplification of the spectral ratio. Amplifications at the resonance frequencies of the Koutavos basin have been observed. These amplifications are in a good agreement with the ones calculated from the measurements, especially between 3 and $4 \mathrm{~Hz}$. A refinement of the geological model of the basin is necessary in order to get closer to the low-frequency. The presence of this structures in the studied site requires a specific analysis that takes into account both the 3-D structure and the soil conditions in order to capture local effects that may be particularly disastrous. Hence, further works include modelling of the Koutavos sedimentary basin will be carried out in order to quantify the effect of topography and bathymetry combined with that of sedimentary fillings on ground motion.

Acknowledgements The work carried out under the SINAPS@ project receives French funding managed by the National Research Agency under the program Future Investments (SINAPS@ reference No. ANR-11-RSNR-0022). SINAPS@ is a SEISM Institute project (http://www.institutseism.fr/en/). This work was performed using HPC resources from the "Mésocentre" computing center of CentraleSupélec and École Normale Supérieure ParisSaclay supported by CNRS and Région Île-de-France (http://mesocentre.centralesupelec.fr/) as well as the Occigen supercomputer. The latter machine is hosted by French National Computing Center for Higher Education - CINES (https://www.cines.fr/en/supercomputing-2/).

\section{References}

Berenger JP (1994) A perfectly matched layer for the absorption of electromagnetic waves. Journal of computational physics 114(2):185-200

Berge-Thierry C, Svay A, Laurendeau A, Chartier T, Perron V, GuyonnetBenaize C, Kishta E, Cottereau R, Lopez-Caballero F, Hollender F, Richard B, Ragueneau F, Voldoire F, Banci F, Zentner I, Moussallam N, Lancieri M, Bard PY, Grange S, Erlicher S, Kotronis P, Le Maoult A, Nicolas M, Régnier 
J, Bonilla F, Theodoulidis N (2017) Toward an integrated seismic risk assessment for nuclear safety improving current french methodologies through the SINAPS@ research project. Nuclear Engineering Design 323(1):185201, DOI 10.1016/j.nucengdes.2016.07.004

Berge-Thierry C, Voldoire F, Ragueneau F, Lopez-Caballero F, Le Maoult A (2019) Main achievements of the multidisciplinary sinaps@ research project: Towards an integrated approach to perform seismic safety analysis of nuclear facilities. Pure and Applied Geophysics DOI 10.1007/s00024-019-02194-4, URL https://doi.org/10.1007/s00024-019-02194-4

Bouchon M (1985) A simple, complete numerical solution to the problem of diffraction of sh waves by an irregular surface. The Journal of the Acoustical Society of America 77(1):1-5

Bouchon M, Barker JS (1996) Seismic response of a hill: the example of tarzana, california. Bulletin of the Seismological Society of America 86(1A):66-72

Bouchon M, Schultz CA, Toksöz MN (1996) Effect of three-dimensional topography on seismic motion. Journal of Geophysical Research: Solid Earth 101(B3):5835-5846

Brune JN (1970) Tectonic stress and the spectra of seismic shear waves from earthquakes. Journal of geophysical research 75(26):4997-5009

Castro Cruz DA (2018) Prédiction des mouvements sismiques forts: apport de l'analyse du comportement non-linéaire des sols et de l'approche des fonctions de green empiriques. PhD thesis, Côte d'Azur

Chaljub E, Capdeville Y, Vilotte JP (2003) Solving elastodynamics in a fluidsolid heterogeneous sphere: a parallel spectral element approximation on non-conforming grids. Journal of Computational Physics 187(2):457-491

Chaljub E, Komatitsch D, Vilotte JP, Capdeville Y, Valette B, Festa G (2007) Spectral-element analysis in seismology. Advances in geophysics 48:365-419

Chávez-Garcıa F, Raptakis D, Makra K, Pitilakis K (2000) Site effects at euroseistest - ii. results from $2 \mathrm{~d}$ numerical modeling and comparison with observations. Soil Dynamics and Earthquake Engineering 19(1):23-39

Cruz-Atienza V, Tago J, Sanabria-Gómez J, Chaljub E, Etienne V, Virieux J, Quintanar L (2016) Long duration of ground motion in the paradigmatic valley of mexico. Scientific reports 6:38807

Cultrera G, Andreou T, Bard PY, Boxberger T, Cara F, Cornou C, Di Giulio G, Hollender F, Imitiaz A, Kementzetzidou D, et al. (2014) The argostoli (cephalonia, greece) experiment. In: Proceedings of the second European conference on earthquake engineering and seismology (2ECEES), Istanbul, Turkey, pp 24-29

Cushing E, Hollender F, Guyonnet-Benaize C, Perron V, Imtiaz A, Svay A, Bard P, Cottereau R, Lopez Caballero F, Theodoulidis N, et al. (2016) Close to the lair of odysseus cyclops: The sinaps@ postseismic campaign and accelerometric network installation on kefalonia island - site effect characterization experiment. Proceedings of the 7th INQUA on paleoseismology, active tectonics and archeoseismology, Crestone, Colorado, USA 30 
Cushing EM, Hollender F, Moiriat D, Guyonnet-Benaize C, Theodoulidis N, Pons-Branchu E, Sepulcre S, Bard PY, Cornou C, Dechamp A, Marsical A, Roumelioti Z (2019) Building a three dimensional model of the active plio-quaternary basin of argostoli (cephalonia island, greece): an integrated geophysical and geological approach. Engineering Geology paper under revision

Faccioli E, Maggio F, Paolucci R, Quarteroni A (1997) 2d and 3d elastic wave propagation by a pseudo-spectral domain decomposition method. Journal of seismology 1(3):237-251

Faccioli E, Vanini M, Frassine L (2002) Complex site effects in earthquake ground motion, including topography. In: 12th European Conference on Earthquake Engineering, vol 844

Festa G, Vilotte JP (2005) The newmark scheme as velocity-stress timestaggering: an efficient pml implementation for spectral element simulations of elastodynamics. Geophysical Journal International 161(3):789-812

Gatti F (2017) Analyse physics-based de scénarios sismiques de la faille au site: prédiction de mouvement sismique fort pour l'étude de vulnérabilité sismique de structures critiques. PhD thesis, Université Paris-Saclay

Gatti F, Lopez-Caballero F, Clouteau D, Paolucci R (2018) On the effect of the 3-d regional geology on the seismic design of critical structures: the case of the kashiwazaki-kariwa nuclear power plant. Geophysical Journal International 213(2):1073-1092

Geli L, Bard PY, Jullien B (1988) The effect of topography on earthquake ground motion: a review and new results. Bulletin of the Seismological Society of America 78(1):42-63

Göddeke D, Komatitsch D, Möller M (2014) Finite and spectral element methods on unstructured grids for flow and wave propagation problems. In: $\mathrm{Nu}-$ merical Computations with GPUs, Springer, pp 183-206

Haslinger F, Kissling E, Ansorge J, Hatzfeld D, Papadimitriou E, Karakostas V, Makropoulos K, Kahle HG, Peter Y (1999) 3d crustal structure from local earthquake tomography around the gulf of arta (ionian region, nw greece). Tectonophysics 304(3):201-218

Hisada Y (1994) An efficient method for computing green's functions for a layered half-space with sources and receivers at close depths. Bulletin of the Seismological Society of America 84(5):1456-1472

Hisada Y (1995) An efficient method for computing green's functions for a layered half-space with sources and receivers at close depths (part 2). Bulletin of the Seismological Society of America 85(4):1080-1093

Hisada Y (2008) Broadband strong motion simulation in layered half-space using stochastic green's function technique. Journal of Seismology 12(2):265279

Hollender F, Perron V, Imtiaz A, Svay A, Mariscal A, Bard P, Cottereau R, Lopez-Caballero F, Cushing E, Theodoulidis N, et al. (2015) A deux pas du repaire du cyclope d'ulysse: la campagne post-sismique et le démarrage du réseau accélérométrique sinaps@ sur l'île de céphalonie. In: Proceedings of the 9th AFPS National Meeting 
Imtiaz A, Perron V, Svay A, Hollender F, Bard P, Theodoulidis N (2017) Wavefield characteristics and coherency of seismic ground motion from a rocksite at argostoli greece. In: Sixteenth World Conference on Earthquake Engineering, 1743

Komatitsch D (1997) Méthodes spectrales et éléments spectraux pour l'équation de l'élastodynamique $2 \mathrm{~d}$ et $3 \mathrm{~d}$ en milieu hétérogène. $\mathrm{PhD}$ thesis, Institut de physique du globe de paris-IPGP

Komatitsch D, Vilotte JP (1998) The spectral element method: an efficient tool to simulate the seismic response of $2 \mathrm{~d}$ and $3 \mathrm{~d}$ geological structures. Bulletin of the seismological society of America 88(2):368-392

Komatitsch D, Tsuboi S, Tromp J, Levander A, Nolet G (2005) The spectralelement method in seismology. Geophysical monograph 157:205

Kristek J, Moczo P, Bard PY, Hollender F, Stripajová S (2018) Computation of amplification factor of earthquake ground motion for a local sedimentary structure. Bulletin of Earthquake Engineering 16(6):2451-2475

Lagios E, Papadimitriou P, Novali F, Sakkas V, Fumagalli A, Vlachou K, Del Conte S (2012) Combined seismicity pattern analysis, dgps and psinsar studies in the broader area of cephalonia (greece). Tectonophysics 524:43-58

Liu Q (2006) Spectral-element simulations of 3-d seismic wave propagation and applications to source and structural inversions. PhD thesis, California Institute of Technology

Louvari E, Kiratzi A, Papazachos B (1999) The cephalonia transform fault and its extension to western lefkada island (greece). Tectonophysics 308(12):223-236

Mayday Y, Patera A, Rønquist E (1989) Optimal legendre spectral element methods for the multi-dimensional stokes problem. SIAM J Num Anal

Meza-Fajardo KC, Semblat JF, Chaillat S, Lenti L (2016) Seismic-wave amplification in 3d alluvial basins: 3d/1d amplification ratios from fast multipole bem simulations. Bulletin of the Seismological Society of America 106(3):1267-1281

O'Connell DR, Ake JP, Bonilla F, Liu P, LaForge R, Ostenaa D (2012) Strong ground motion estimation. In: Earthquake Research and Analysis-New Frontiers in Seismology, InTech

Paolucci R, Mazzieri I, Smerzini C (2015) Anatomy of strong ground motion: near-source records and three-dimensional physics-based numerical simulations of the mw 6.02012 may 29 po plain earthquake, italy. Geophysical Journal International 203(3):2001-2020, DOI 10.1093/gji/ggv405

Patera AT (1984) A spectral element method for fluid dynamics: laminar flow in a channel expansion. Journal of computational Physics 54(3):468-488

Perron V, Hollender F, Mariscal A, Theodoulidis N, Andreou C, Bard PY, Cornou C, Cottereau R, Cushing EM, Frau A, et al. (2018a) Accelerometer, velocimeter dense-array, and rotation sensor datasets from the sinaps@ postseismic survey (cephalonia 2014-2015 aftershock sequence). Seismological Research Letters 89(2A):678-687

Perron V, Hollender F, Mariscal A, Theodoulidis N, Andreou C, Bard PY, Cornou C, Cottereau R, Cushing EM, Frau A, et al. (2018b) Accelerome- 
ter, velocimeter dense-array, and rotation sensor datasets from the sinaps@ postseismic survey (cephalonia 2014-2015 aftershock sequence). Seismological Research Letters 89(2A):678-687

Pitarka A, Irikura K, Iwata T, Kagawa T (1996) Basin structure effects in the kobe area inferred from the modeling of ground motions from two aftershocks of the january 17, 1995, hyogo-ken nanbu earthquake. Journal of Physics of the Earth 44(5):563-576

Rezaeian S, Der Kiureghian A (2012) Simulation of orthogonal horizontal ground motion components for specified earthquake and site characteristics. Earthquake Engineering and Structural Dynamics 41(2):335-353

Riga E, Makra K, Pitilakis K (2016) Aggravation factors for seismic response of sedimentary basins: A code-oriented parametric study. Soil Dynamics and Earthquake Engineering 91:116-132

Sbaa S, Hollender F, Perron V, Imtiaz A, Bard PY, Mariscal A, Cochard A, Dujardin A (2017) Analysis of rotation sensor data from the sinaps@ kefalonia (greece) post-seismic experiment - link to surface geology and wavefield characteristics. Earth, Planets and Space 69(1):124

Simo JC (1992) Algorithms for static and dynamic multiplicative plasticity that preserve the classical return mapping schemes of the infinitesimal theory. Computer Methods in Applied Mechanics and Engineering 99(1):61-112

Sokos E, Zahradník J, Gallovič F, Serpetsidaki A, Plicka V, Kiratzi A (2016) Asperity break after 12 years: the mw6. 42015 lefkada (greece) earthquake. Geophysical Research Letters 43(12):6137-6145

Spudich P, Hellweg M, Lee W (1996) Directional topographic site response at tarzana observed in aftershocks of the 1994 northridge, california, earthquake: implications for mainshock motions. Bulletin of the Seismological Society of America 86(1B):S193-S208

Svay A, Perron V, Imtiaz A, Zentner I, Cottereau R, Clouteau1 D, Bard PY, Hollender F, Lopez-Caballero F (2017) Spatial coherency analysis of seismic ground motions from a rock site dense array implemented during the kefalonia 2014 aftershock sequence. Earthquake Engineering \& Structural Dynamics 46(12):1895-1917

Theodoulidis N, Cultrera G, Cornou C, Bard PY, Boxberger T, DiGiulio G, Imtiaz A, Kementzetzidou D, Makra K, Team AN, et al. (2018) Basin effects on ground motion: the case of a high-resolution experiment in cephalonia (greece). Bulletin of Earthquake Engineering 16(2):529-560

Touhami S, Lopez-Caballero F, Clouteau D (2019) Numerical analysis of local geology effects on ground motion prediction. In: Proceedings of 13th International Conference on Applications of Statistics and Probability in Civil Engineering, ICASP13, Seoul, South Korea

Volpini C, Douglas J (2019) An accessible approach for the site response analysis of quasi-horizontal layered deposits. Bulletin of Earthquake Engineering $17(3): 1163-1183$

Zhou H, Chen X (2006) A new approach to simulate scattering of sh waves by an irregular topography. Geophysical Journal International 164(2):449-459 